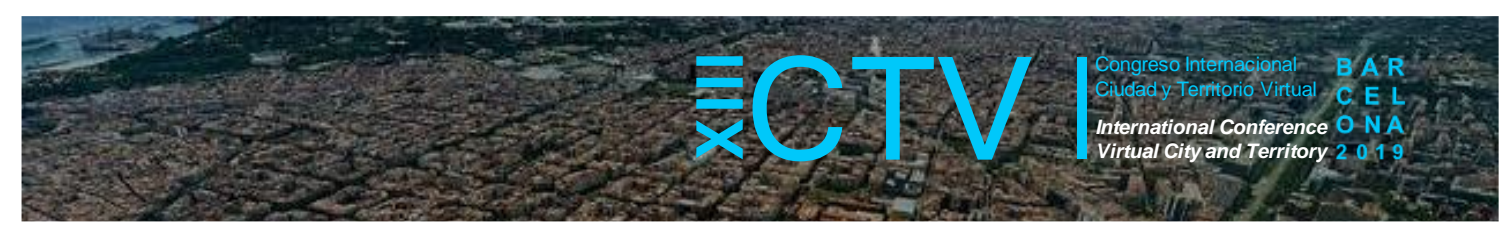

\title{
INSTRUMENTOS DE FINANCIACIÓN PARA LA EDIFICACIÓN EFICIENTE: ANÁLISIS DE BONOS E HIPOTECAS VERDES
}

\author{
Souto, Raquel ${ }^{1}$; Morales, Paloma ${ }^{2}$; Espinoza, Paúl ${ }^{3}$; Vargas, Patricia ${ }^{4}$ y Marmolejo, Carlos ${ }^{5}$
}

Remisión inicial: 2019-MM-DD; Remisión definitiva: 2019-MM-DD; Publicación: 2019-12-21

Citation: Souto, R. et al. (2019). Instrumentos de financiación para la edificación eficiente: análisis de bonos e hipotecas verdes. XIII CTV 2019 Proceedings: XIII International Conference on Virtual City and Territory: "Challenges and paradigms of the contemporary city": UPC, Barcelona, October 2-4, 2019. Barcelona: CPSV, 2019, p. 8628. E-ISSN 2604-6512. DOI http://dx.doi.org/10.5821/ctv.8628

\section{Resumen}

El presente documento es el resultado final de la asignatura "Seminario de Investigación" de la línea Gestión y Valoración Urbana y Arquitectónica, en el máster MBArch de la Universidad Politécnica de Catalunya.

Según el Programa de la Naciones Unidas para el Desarrollo, las medidas que tomemos hoy con respecto al cambio climático tendrán consecuencias que perdurarán por un siglo o más. El parque edificatorio, responsable de un alto porcentaje de la generación de $\mathrm{CO} 2$ y del consumo total de energía (en la Unión Europea, los edificios son responsables del $36 \%$ de la generación del dióxido de carbono y del $40 \%$ del consumo final de energía) acapara la atención de los gobiernos y la comunidad internacional, preocupada por la generación de estrategias para limitar las emisiones de carbono. El volumen de capital gestionado por el sector financiero invita a los gobiernos a colaborar con el mismo en la creación de un nuevo parque inmobiliario más eficiente energéticamente. El Acuerdo de París y los programas y normativas derivados del mismo, fomentan la creación de instrumentos de financiación verde por parte del sector público y privado.

El objetivo principal del estudio es desarrollar un estado del arte sobre la financiación verde: en qué consiste, cuáles son sus antecedentes en lo relativo a acuerdos y normativas, y cuáles son los tipos fundamentales y los ejemplos más destacados. Nos centramos especialmente en dos instrumentos de financiamiento: bonos verdes (a escala global) e hipotecas verdes (en los Estados Unidos, México y la Unión Europea, con especial énfasis en España), además de dos experiencias previas de financiación fuera de esta clasificación: el caso inglés Green Deal y el alemán EnEv.

La metodología utilizada consiste en una revisión, registro y análisis de diferentes fuentes de información clasificadas en: a) artículos científicos, b) documentos normativos y c) páginas web institucionales, sobre el financiamiento verde y sus principales instrumentos (bonos e hipotecas verdes), analizados desde la perspectiva de la regulación, difusión y aplicación.

El análisis ha revelado que realmente no existe una estandarización para la emisión y certificación en ninguno de los casos de financiación verde. Existe una búsqueda por homogeneizar dichos procesos, siendo los bonos verdes quienes llevan ventaja sobre otros mecanismos de financiación. En el panorama hipotecario, la desinformación para el prestatario en el acceso, la inexistencia de un sistema de certificación único que facilite la regulación, la posible inseguridad para el inversor, la muy limitada oferta de productos en países como España, las desigualdades aparejadas al acceso a este tipo de productos, así como la tendencia a la localización en la periferia de las viviendas registradas con este tipo de financiación, son algunas de las limitaciones observadas durante el estudio.

\section{Abstract}

This document is the result of the subject Research Seminar, imparted by the Urban and Architectural Management and Valuation line, at the MBArch Master of the Polytechnic University of Catalonia. According to the United Nations Development Program, the measures we take today regarding climate change will have consequences that will last for a century or more. Building stock, responsible for a high percentage of $\mathrm{CO} 2$ generation and total energy consumption (in

\footnotetext{
${ }^{1}$ Universitat Politècnica de Catalunya - https://orcid.org/0000-0002-8306-6384, ${ }^{2}$ Universitat Politècnica de Catalunya https://orcid.org/0000-0002-6977-6013, ${ }^{3}$ Universitat Politècnica de Catalunya - https://orcid.org/0000-0003-4346-8917, ${ }^{4}$ Universitat Politècnica de Catalunya - https://orcid.org/0000-0001-9855-5319 y $y^{5}$ Universitat Politècnica de Catalunya https://orcid.org/0000-0001-7051-7337.
} 


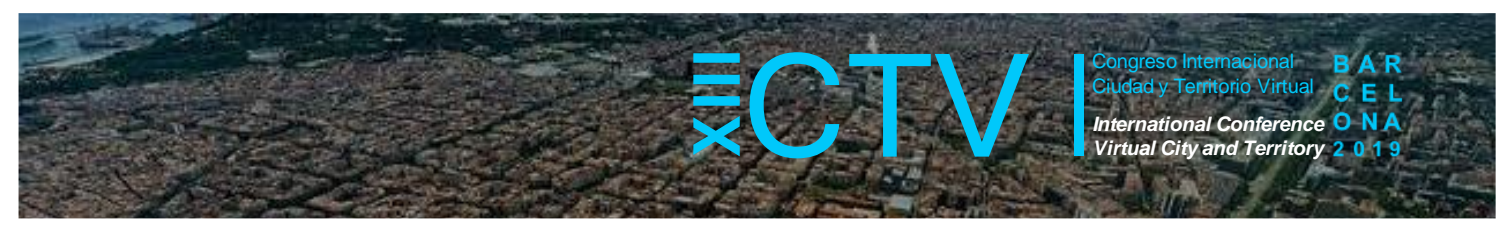

the European Union, buildings are responsible for $36 \%$ of the generation of carbon dioxide and $40 \%$ of final energy consumption) attracts the attention of governments and the international community, concerned with the generation of strategies to limit carbon emissions. The volume of capital managed by the financial sector invites governments to collaborate with it in the creation of a new, more energy-efficient housing stock. The Paris Agreement and the programs and regulations derived from it promote the creation of green financing instruments by the public and private sectors. The main objective of the study is to develop a state of the art on green financing: what is it, what are its antecedents in relation to agreements and regulations, what are the fundamental types and the most prominent examples. We focus especially on two financing instruments: green bonds (on a global scale) and green mortgages (in the United States, Mexico and the European Union, with special emphasis on Spain), in addition to two previous financing experiences outside this classification: The English case Green Deal and the German EnEv. The methodology used consists of a review, registration and analysis of different sources of information classified in: a) scientific articles, b) normative documents and c) institutional web pages, on green financing and its main instruments (green bonds and mortgages), analyzed from the perspective of regulation, dissemination and application. The analysis has revealed that there is no standardization for issuance and certification in any of the green funding cases. There is a search to homogenize these processes, with green bonds being the advantage over other financing mechanisms. In the mortgage outlook, the borrower disinformation about access; the lack of a single certification system that facilitates regulation; the possible insecurity for the investor; the very limited supply of products in countries such as Spain; the inequalities associated with access to these types of products, as well as the tendency to locate on the periphery of the homes registered with this type of financing, are some of the limitations observed during the study.

Palabras Clave: finanzas verdes; certificado energético; eficiencia energética.

Key words: green finance; energy certificate; energy efficiency.

\section{Contexto: la financiación verde y sus instrumentos}

El papel del sector de la edificación en el consumo energético y las emisiones de carbono es evidente, al igual que su capacidad transformadora sobre las mismas. Según la Directiva de Eficiencia Energética de Edificios (2018), en la Unión Europea, los edificios son responsables del $36 \%$ de la generación del dióxido de carbono y del $40 \%$ del consumo final de energía. Así, el parque edificatorio, responsable de un alto porcentaje de la generación de $\mathrm{CO}_{2}$ y del consumo total de energía acapara la atención de los gobiernos y la comunidad internacional, preocupada por la generación de estrategias para limitar las emisiones de carbono. Los datos demuestran que, atendiendo a la eficiencia energética, un edificio con una categoría " $E$ " emite 8.50 veces más $\mathrm{CO}_{2}$ y consume cuatro veces más energía que uno con una clase "A". También el calificado como "E" genera una demanda de calefacción 2.35 veces superior al calificado como "A". La comparativa del consumo de una vivienda en un bloque en el municipio de Castelló d'Empúries Catalunya (Ver Figura 1), es un ejemplo de las potencialidades de la reducción de emisiones a través de la mejora de la eficiencia del parque edificado.

Figura 1. Comparativa del consumo de energía final de un edificio en relación con la media

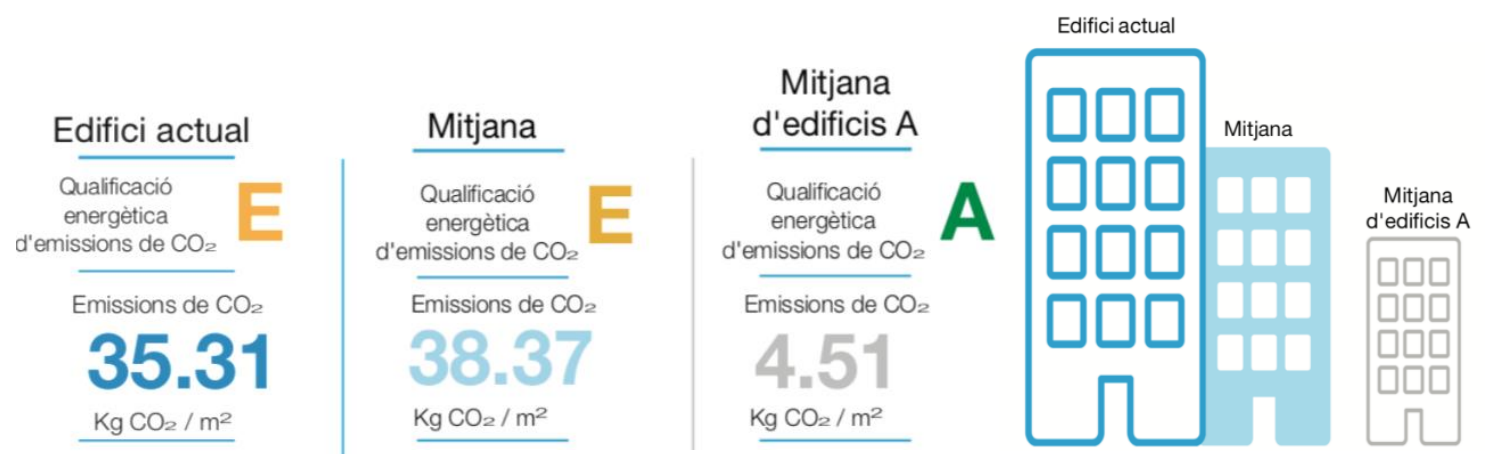

Fuente: Informe del gasto energético del edificio (Instituto Catalán de Energía). 


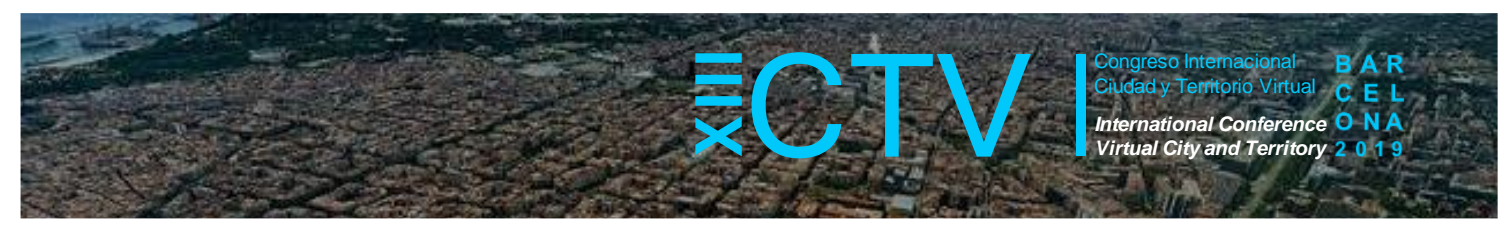

El Acuerdo de París, dependiente de la finalización del Protocolo de Kyoto, da fe de esta intención de introducir el sector de la edificación como clave en el proceso de la descarbonización energética, y es el punto de partida para una serie de programas que intentan vincular la eficiencia energética de las edificaciones con la financiación de estas. El Acuerdo promueve la participación y coordinación de los sistemas financieros globales en conjunción con la inversión institucional, cuyo objetivo es fomentar una expansión masiva de los flujos de inversión públicos y privados hacia economías bajas en carbono (Global Climate Action Summit, 2019). Para este propósito se emplazan desde los ministerios de hacienda, bancos centrales, instituciones financieras, cooperativas y sector del "microfinanciamiento", hasta a los actores productivos de pequeñas y medianas empresas. A estas iniciativas se las coloca dentro del concepto de "financiación verde".

El Acuerdo de París es sólo el ejemplo más reciente de una trayectoria de encuentros internacionales entre los gobiernos preocupados con el cambio climático y sus consecuencias. En 1988 se creó el Grupo Intergubernamental de Expertos sobre el Cambio Climático (IPCC, por sus siglas en inglés), que tuvo origen en la Convención Marco de las Naciones Unidas y el posterior Protocolo de Kyoto de 1997. Posteriormente, se han realizado múltiples Convenciones de las Partes (COP, por sus siglas en inglés) (ONU, 2018), en las que se revisan y toman decisiones para la implementación efectiva de los diversos acuerdos (Ver Figura 2). En la actualidad, el mencionado Acuerdo de París es el instrumento legal en vigor, pero su aplicación de obligaciones inicia en el año 2020, que es cuando finaliza el Protocolo de Kyoto (La decimoctava Convención de las Partes sobre cambio climático ratificó el segundo período de vigencia del Protocolo de Kyoto desde enero de 2013 hasta diciembre de 2020).

Figura 2. Línea de tiempo de las COP y Acuerdos Climáticos

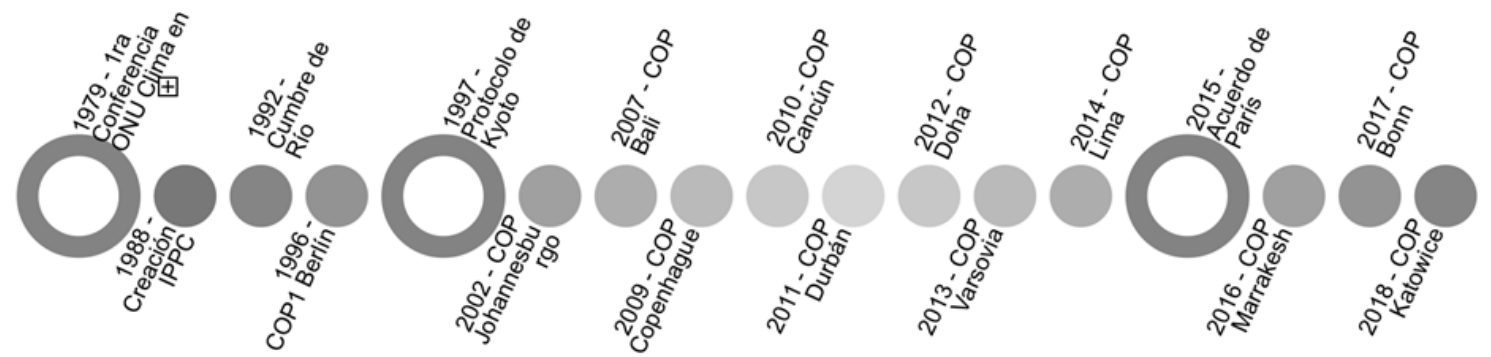

Fuente: Elaboración propia con datos de la ONU (2015).

El Acuerdo de París fue aprobado en 2016 una vez ratificado por los 55 países responsables de al menos el $55 \%$ de las emisiones mundiales. Esta colaboración mundial promete reducir las emisiones globales de efecto invernadero con un objetivo fundamental: la creación de un Plan de Acción para limitar el calentamiento del planeta por debajo de los $2^{\circ} \mathrm{C}$ respecto a los niveles preindustriales. El ambicioso acuerdo trabaja sobre tres líneas clave:

- La preocupación sobre el aumento de la temperatura y su mitigación.

- El aumento de la resiliencia, capacidad de adaptación a los efectos adversos del cambio climático.

- Generar una atracción y colaboración con el capital financiero, invitándolo a participar en los objetivos del Acuerdo de París de reducción de emisiones y control de la temperatura.

El Acuerdo tiene virtudes como la de introducir mecanismos de coordinación institucional o universalizar las exigencias de reducción de emisiones a todos los países. Sin embargo, la retirada de actores de relevancia en la firma del Acuerdo (como la ya efectiva salida de los 


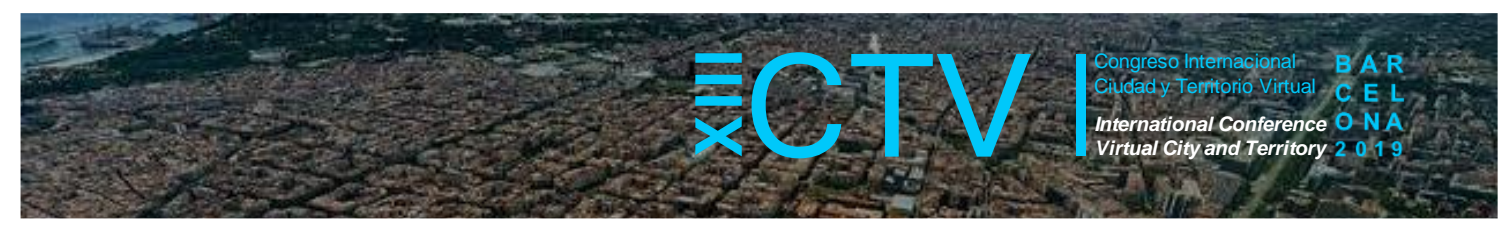

Estados Unidos) y consecuencias derivadas como la disminución de la contribución al fondo global de lucha contra el cambio climático, evidencian la dificultad de su aplicación. Con el propósito de trascender los objetivos del Acuerdo de París y para desarrollar una hoja de ruta sobre las finanzas verdes en la Unión Europea, la Comisión Europea creó en el año 2016 el Grupo de Alto Nivel sobre Finanzas sostenibles (HLEG, por sus siglas en inglés). Integrado por 20 miembros de la sociedad civil, sector financiero, académico y observadores de instituciones europeas e internacionales (Comisión Europea, 2016), crea el documento "Final Report by the High-Level Expert Group on Sustainable Finance" (Financial Stability, Financial Services and Capital Markets Union, 2018), el cual recoge una serie de recomendaciones relacionados con la estandarización o la importancia de la divulgación de instrumentos financieros relacionados a la transición energética (ver Tabla 1).

Tabla 1. Recomendaciones del HLEG

\begin{tabular}{lll}
\hline \multicolumn{1}{c}{ Prioritarias } & \multicolumn{1}{c}{ Transversales } & \multicolumn{1}{c}{ Sector financiero } \\
\hline $\begin{array}{l}\text { Establecer una etiqueta de sostenibilidad } \\
\text { común para toda la UE. }\end{array}$ & $\begin{array}{l}\text { Considerar formas de } \\
\text { empoderamiento ciudadano } \\
\text { con la financiación sostenible. }\end{array}$ & $\begin{array}{l}\text { Promover préstamos de economía } \\
\text { real y sostenibilidad en el sector } \\
\text { bancario. }\end{array}$ \\
\hline $\begin{array}{l}\text { Clarificar los deberes de los inversores } \\
\text { con el fin de ampliar. los horizontes } \\
\text { temporales de la inversión. }\end{array}$ & $\begin{array}{l}\text { Supervisar los planes de } \\
\text { inversión a través de un } \\
\text { observatorio. }\end{array}$ & $\begin{array}{l}\text { Habilitar a las compañías } \\
\text { aseguradoras para tener un rol más } \\
\text { importante en las inversiones de } \\
\text { capital a largo plazo y de } \\
\text { infraestructura. }\end{array}$ \\
\hline $\begin{array}{l}\text { Mejorar la divulgación de la importancia de } \\
\text { la sostenibilidad en las decisiones de } \\
\text { entidades financieras. }\end{array}$ & $\begin{array}{l}\text { Garantizar que las normas } \\
\text { contables no desalienten la } \\
\text { inversión de largo plazo. }\end{array}$ & $\begin{array}{l}\text { Garantizar mayor comprensión de } \\
\text { las preferencias de sostenibilidad de } \\
\text { los clientes con los administradores } \\
\text { de activos, fondos de pensiones y } \\
\text { consultores de inversiones. }\end{array}$ \\
\hline $\begin{array}{l}\text { Desarrollar estándares de financiación } \\
\text { sostenible para algunos activos } \\
\text { financieros. (Bonos verdes, fondos de } \\
\text { inversión ecológicos). }\end{array}$ & $\begin{array}{l}\text { Establecer el principio de la } \\
\text { sostenibilidad en el diseño de } \\
\text { las políticas públicas. }\end{array}$ & $\begin{array}{l}\text { Obtener mejor investigación a largo } \\
\text { plazo por parte de los bancos de } \\
\text { inversión. }\end{array}$ \\
$\begin{array}{l}\text { Integrar la sostenibilidad en la gobernanza } \\
\text { de las instituciones y la supervisión } \\
\text { financieras. }\end{array}$ & $\begin{array}{l}\text { Impulsar la financiación } \\
\text { sostenible a nivel global. }\end{array}$ & \\
\hline
\end{tabular}

Fuente: Elaboración propia con datos del HLEG.

Estas recomendaciones fueron plasmadas en el "Plan de Acción para Financiar el Desarrollo Sostenible" de la Comisión Europea, que pretende, entre otros objetivos, clasificar los "productos verdes" con el propósito de orientar a los inversores. Aunque el HLEG sostiene la necesidad de elaborar también una etiqueta de sostenibilidad común para toda la Unión Europea (con el fin de garantizar la claridad y consistencia del mercado de proyectos sostenibles), esta etiqueta única es todavía una quimera, ya que su estandarización demanda un mismo marco normativo de calificación de parámetros. La dificultad es evidente puesto que, por obvias diferencias de índole geográfica, no existe un patrón único sobre qué es energéticamente eficiente. No obstante, para garantizar el cumplimiento de las recomendaciones del HLEG y los objetivos de la UE, ha sido necesario modificar normativas europeas. Una de estas normativas es la Guía de Eficiencia Energética en Edificios (EPBD, por sus siglas en inglés). Como puede verse en la Figura 3, la EPBD 2018/844/UE contiene modificaciones con base en el Acuerdo de París y las recomendaciones del HLEG por parte de la Comisión Europea. La primera versión de la EPBD (en aquel entonces SAVE) data de 1993 (Unión Europea, 2019), mucho antes de entrar en vigor el Protocolo de Kyoto. Aunque no era vinculante, ya incluía una lista de acciones que los Estados Miembros debían impulsar para optimizar la eficiencia energética en los edificios, entiéndase: esquemas normativos como la certificación energética de edificios (reforzados en las posteriores versiones), el aislamiento térmico y la inspección periódica de calderas. 


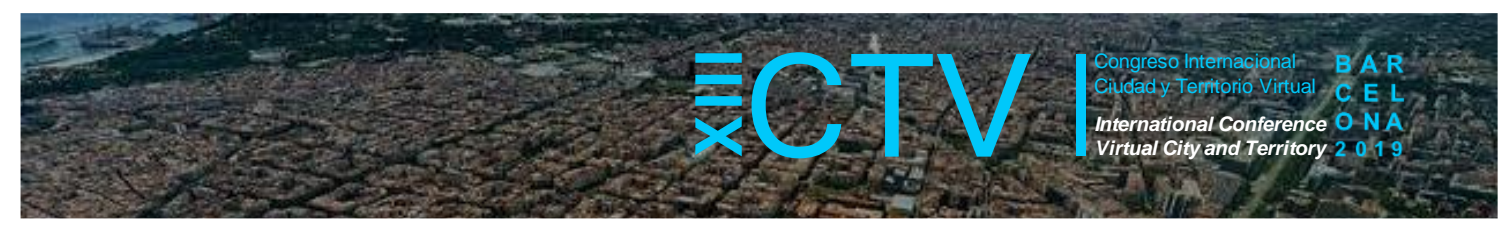

Figura 3. Aportaciones de la EPBD según el Acuerdo de París y el HLEG
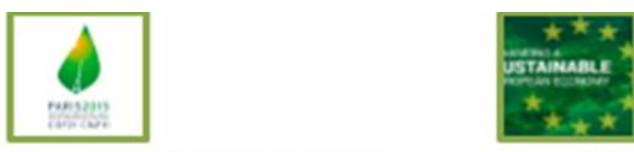

- Mantener a largo plazo

el aumento de la

temperatura media

mundial muy por debajo

de $2^{\circ} \mathrm{C}$ sobre los niveles

preindustriales y tratar

de reducirlo a $1.5^{\circ} \mathrm{C}$.

- Aumentar la capacidad

de adaptación a los

efectos adversos del

cambio climático y

promover la resiliencia al

clima y un desarrollo con

bajas emisiones de

gases de efecto

invernadero, de un modo

que no comprometa la

producción de alimentos.

- Los paises acordaron

comunicar cada 5 años

sus contribuciones para

fijar objetivos más

ambiciosos.

- La UE apoyará

financiando la lucha

contra el cambio

climático para ayudar a

los paises en desarrollo.

- Creación de actos
legislativos que incluyan
medidas que aceleren el
ritmo de renovación de
edificios hacia sistemas
más eficientes
- Fortalecer el rendimiento
energético de los
edificios, haciéndolos
más inteligentes
mediante un paquete de
"Energía Limpia' de
adopción para toda la
UE, que incluye:
- Directiva de rendimiento
energético en edificios.
- Directiva de Energias
Renovables.
- Directiva de Eficiencia
Energética.
- Regulación de la
gobernanza.
- Directiva eléctrica.
- Reglamento de
electricidad.
- Reglamento de
preparación ante
riesgos.
- Reglamento de la
Agencia de Cooperación
de los Reguladores de la
Energia.

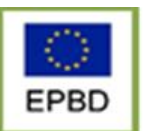

- Nuevas aportaciones 2010/31/UE

- Creación de pautas de

convergencia de

Requisitos de Eficiencia

Energética.

- Introducción del

concepto: Edificios de

Consumo Energético

Casi Nulo (nZEB).

- Mayor desarrollo en el

contenido de los

Certificados de

Eficiencia Energética en

relación a los niveles

óptimos de eficiencia

estimación de

recuperación de

inversión o rentabilidad

en vida útil.

- Se obliga a la obtención

de CEE a edificios

ocupados por

autoridades públicas

mayores de $500 \mathrm{~m}^{2}$

frecuentados por el

público.

- Obligación a mostrar e

indicador de eficiencia.

El mandato aplica a

construcciones desde

$250 \mathrm{~m}^{2}$.

Fuente: Elaboración propia con datos del Acuerdo de París, el HLEG y la EPBD.

Además de estas iniciativas en cuanto a la regulación y normativización, la línea de actuación de la Unión Europea va encaminada a una colaboración con el sector financiero, haciéndolo partícipe y actor clave en la descarbonización energética mediante la "financiación verde" (Unión Europea, 2019). Llamamos finanzas verdes a los procesos comerciales y financieros que tienen en cuenta la sostenibilidad, eficiencia energética o reducción de emisiones, abarcando este concepto un ámbito amplio, incluyendo temas relacionados con el suelo, los bosques, el agua, los océanos, o la conservación y la adaptación al cambio (Santander, 2018).

Los países desarrollados fomentan el financiamiento verde en países en vías de desarrollo a través de fondos como el Fondo Mundial para el Medio Ambiente (GEF, por sus siglas en inglés), mecanismo financiero de la Convención Marco de Naciones Unidas sobre el Cambio Climático, o el Fondo Verde del Clima (GCF, por sus siglas en inglés). Algunos productos relacionados con la financiación verde, como préstamos y bonos verdes, se han destacado por el impulso dado en el último año (Figura 4).

Los préstamos verdes se definen como cualquier tipo de instrumento de préstamo disponible exclusivamente para financiar, en su totalidad o en parte, proyectos verdes nuevos o existentes (Hussain, 2018). Para que un préstamo sea considerado verde, debe estar certificado por un organismo externo como un instrumento para promover la sostenibilidad medioambiental (Hernández, 2017). En la Tabla 2 se describen los cuatro principales formatos de préstamos verdes. 


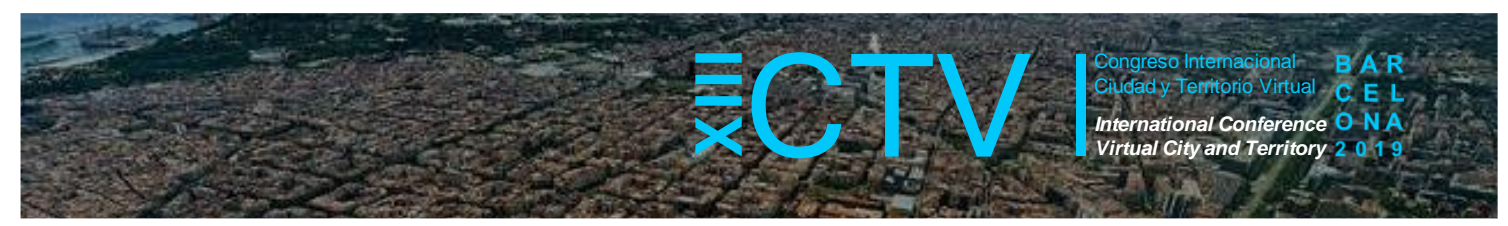

Figura 4. Emisión anual de deuda sostenible en el mundo

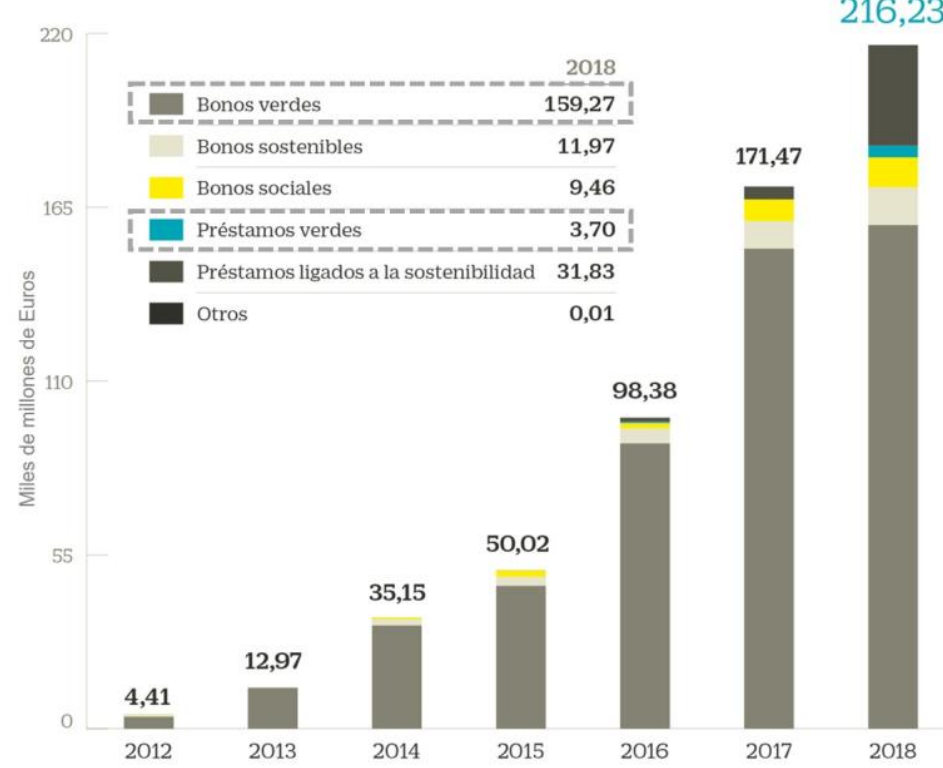

Fuente: BloombergNEF y Bloomberg (2018).

Los préstamos verdes se definen como cualquier tipo de instrumento de préstamo disponible exclusivamente para financiar, en su totalidad o en parte, proyectos verdes nuevos o existentes (Hussain, 2018). Para que un préstamo sea considerado verde, debe estar certificado por un organismo externo como un instrumento para promover la sostenibilidad medioambiental (Hernández, 2017). En la Tabla 2 se describen los cuatro principales formatos de préstamos verdes.

Tabla 2. Formatos principales de préstamos verdes

\begin{tabular}{llll}
\hline $\begin{array}{l}\text { Préstamo bilateral } \\
\text { "Green Bilateral Loan" }\end{array}$ & $\begin{array}{l}\text { Préstamo sindicado "Green } \\
\text { Syndicated Loan" }\end{array}$ & $\begin{array}{l}\text { Línea de crédito "Green } \\
\text { Revolving Credit Facility" }\end{array}$ & $\begin{array}{l}\text { Financiación de proyecto } \\
\text { "Green Project Finance" }\end{array}$ \\
\hline Operación con garantía & La operación se financia con & Operación basada en una & Operación basada \\
corporativa formalizada & un grupo de bancos y con la & puntuación & fundamentalmente en \\
entre la compañía y el & figura de uno de ellos como & medioambiental, social y & flujos de caja a largo \\
banco. & $\begin{array}{l}\text { banco agente } \\
\text { medioambiental, que se }\end{array}$ & $\begin{array}{l}\text { mayor sea la puntuación, } \\
\text { menos intereses paga la }\end{array}$ & $\begin{array}{l}\text { plazo. Se toman los } \\
\text { proyectos financiados ados }\end{array}$ \\
& $\begin{array}{l}\text { encarga de gestionar y } \\
\text { centralizar la documentación } \\
\text { correspondiente con la }\end{array}$ & compañía, y viceversa. & como garantía. \\
& agencia de calificación. & & \\
\hline
\end{tabular}

Fuente: Elaboración propia con datos de Hernández (2018).

Las hipotecas verdes o también llamadas hipotecas de eficiencia energética (EEM, por sus siglas en inglés), se conciben como préstamos hipotecarios que tienen en cuenta la eficiencia energética de la vivienda para ofrecer beneficios económicos. Es decir, en las hipotecas verdes, la calificación energética del inmueble y el tipo de interés van relacionados tanto en la compra de vivienda, como por la ejecución de reformas. El sentido es que, mientras menos contaminante sea el inmueble, menor será la tasa de interés hipotecario.

El reto para las hipotecas verdes radica en hacerlas competitivas, tanto para un posible cliente que perciba el valor de este producto financiero, como para las entidades que lo ofertan. En Estados Unidos, país en que se creó la figura de las hipotecas verdes en 1980, aun para el año 2006 menos del 1\% de todos los préstamos eran hipotecas verdes (Tedeschi, 2006). En el ámbito 


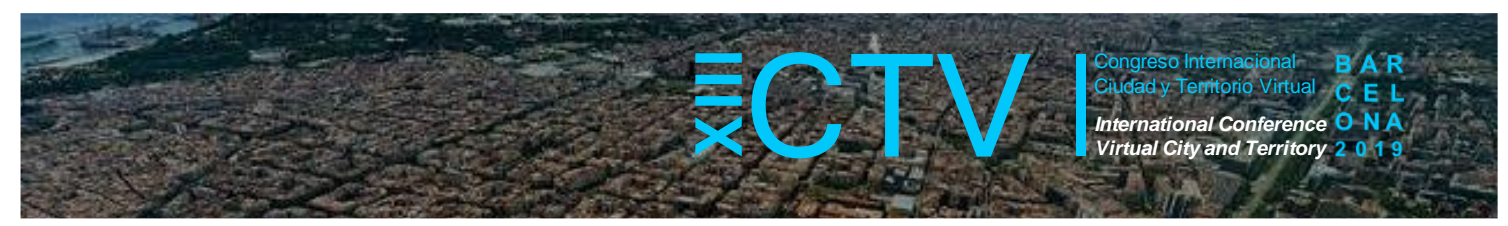

local, recién en 2013 llegan las hipotecas verdes al mercado español, tratándose de un producto clave para cumplir con los objetivos de reducción de emisiones de $\mathrm{CO}_{2}$ de la Unión Europea. El Banco Mundial, por otra parte, define a los bonos verdes como títulos de deuda de renta fija emitidos por organismos multilaterales, entes públicos estatales/municipales o entidades financieras y no financieras de carácter privado, quienes se comprometen a pagar una tasa de interés fija y a entregar la inversión inicial en una fecha de vencimiento (Grupo Banco Mundial, 2015). La emisión de Bonos Verdes ha despegado en los últimos años presentando un crecimiento sustancial. Según un informe de Climate Bonds Initiative (2018), para el año 2018 ya existen 498 emisores de bonos verdes provenientes en su mayoría de Europa. Asia y Norteamérica.

\section{Objetivos}

El presente estudio aborda el ámbito del financiamiento verde: en qué consiste, cuáles son sus antecedentes en lo relativo a acuerdos y normativas, y cuáles son los tipos fundamentales y los ejemplos más destacados. Se centra especialmente en dos instrumentos de financiamiento: bonos e hipotecas verdes, estudiados desde la perspectiva de su regulación, aplicación y difusión, bajo dos objetivos fundamentales:

- Definir qué son los bonos verdes, determinar los procedimientos que se han seguido para su aplicación y conocer los mecanismos de emisión llevados a cabo por los diversos actores públicos y privados que los han utilizado.

- Definir qué son las hipotecas verdes y establecer cuáles han sido los modelos de desarrollo en Estados Unidos, México y la Unión Europea, poniendo especial atención a la situación en España, y analizando para todos ellos la historia de las hipotecas verdes y su funcionamiento.

\section{Metodología}

La metodología utilizada consiste en una revisión, registro y análisis de diferentes fuentes de información clasificadas en: a) Artículos científicos, b) Documentos normativos y c) Páginas web institucionales, sobre el financiamiento verde y los instrumentos objeto de estudio, analizados desde su regulación, difusión y aplicación.

En la primera clasificación (artículos científicos) destacan los estudios de Reboredo (2018), Gianfrate y Peri (2019) y Mclnerney (2019), quienes estudian la conveniencia de invertir en financiación verde en contraposición al financiamiento convencional. Sobre la importancia del papel del gobierno y las políticas públicas en la financiación verde, resaltan los trabajos de Simons et al. (2009), Rosenow et al. (2017), y Lam y Law (2018); asimismo, Simons et al. (2009) junto con Sanderford (2015) indagan en la importancia de la promoción y difusión de la eficiencia energética desde un punto de vista hipotecario. Desde el enfoque del incumplimiento del pago de hipotecas, el trabajo con mayores aportaciones es el de Kaza (2013).

La segunda clasificación (documentos normativos), nos permite hacer un recorrido cronológico por los primeros reglamentos o acuerdos institucionales de carácter legal preocupados por cambio climático. Partimos de acuerdos vinculantes como el Protocolo de Kyoto (1997) y el Acuerdo de París (2016), para proceder al estudio de planes y reglamentos; por una parte, a escala intergubernamental como el "Plan de acción para financiar el desarrollo sostenible", (2019) y el "Final Report by the High Level Expert Group of Sustainable Finance", (2018), y por otra parte a escala nacional como el Plan Making Home Affordable (2009) en los Estados Unidos y el Reglamento del Enev (2002) en Alemania. 


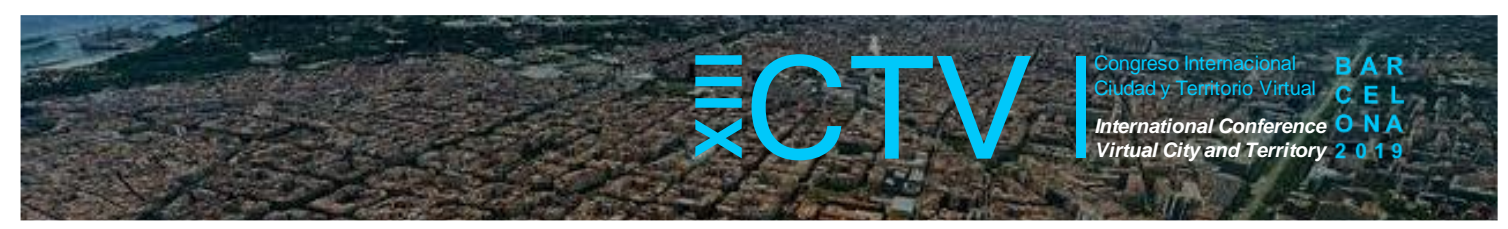

La tercera clasificación (páginas web institucionales) incluye todos los sitios que brindan información institucional y verificada de Institutos, Asociaciones y Administraciones de vivienda en México y los Estados Unidos, como el Instituto del Fondo Nacional para Vivienda de los Trabajadores (INFONAVIT), Federal National Mortgage Association, Federal Home Loan Mortgage Corporation y Federal Housing Administration. Otros sitios web incluyen plataformas encargadas de la certificación y difusión del financiamiento verde, como el caso de la página online "Climate Bonds Initiative" y "The Global Bond Partnership".

La clasificación anteriormente descrita ha permitido establecer:

- Los principales estudios científicos y empíricos que analizan el impacto de la inversión en finanzas verdes. Se examinan aspectos como la importancia de adopción de instrumentos de financiación verde, el papel del gobierno y las políticas públicas, la importancia de la promoción y difusión de la eficiencia energética, así como la relación entre la eficiencia energética y el impago de las hipotecas verdes.

- Una cronología de la aparición de las distintas figuras públicas o privadas que se han encargado de regular y difundir el financiamiento de proyectos alineados al cambio climático.

- La estructura y definición del concepto de los instrumentos de financiación verde que se estudian.

- Los distintos ejemplos de instrumentos para la financiación verde en la Unión Europea, Estados Unidos, México y España. Su proceso, condiciones financieras y el estudio de casos empíricos.

- Escenarios probables de financiación por medio de simulaciones online, que permiten, mediante la introducción de datos personales como localidad, salario mensual, zona bioclimática, entre otros, acceder a un esquema probable de financiación verde para una vivienda. De esta manera se pudo conocer el monto mensual de ahorro financiero que se podría alcanzar al elegir un cierto grupo de dispositivos o sistemas de sustentabilidad habitacional.

- Conclusiones y discusión desde perspectivas como la regulación, difusión y aplicación. De igual manera se hacen distintos abordajes desde aspectos como la desinformación, la inexistencia de un sistema de certificación único, la inseguridad para el inversor/banco, y la oferta reducida de productos.

\section{Instrumentos para la financiación verde}

La disponibilidad actual de líneas de financiamiento verde nace de los compromisos adquiridos por las entidades bancarias y los gobiernos estatales en busca de la sostenibilidad ambiental. A continuación, se ha elaborado una reseña sobre bonos e hipotecas verdes, como principales instrumentos de financiamiento. Debido a la homogeneidad en los criterios de certificación de los bonos verdes, estos se han analizado de forma general, es decir, su funcionamiento, certificación y aplicación a escala global. Las hipotecas verdes, sin embargo, son productos promovidos por la colaboración entre entidades bancarias y organismos públicos en cada país, por lo tanto, han sido estudiadas según su desarrollo en distintos ámbitos territoriales.

\subsection{Bonos verdes}

De acuerdo con el Banco Mundial, los bonos verdes son una forma de título de deuda. Los títulos de deuda constituyen un contrato legal por dinero adeudado que se puede vender y comprar entre distintas partes que se convierten en acreedores de la entidad emisora. Cobran una tasa de interés fija (cupón) y recuperan la inversión inicial (capital) en la fecha de vencimiento. Dado 


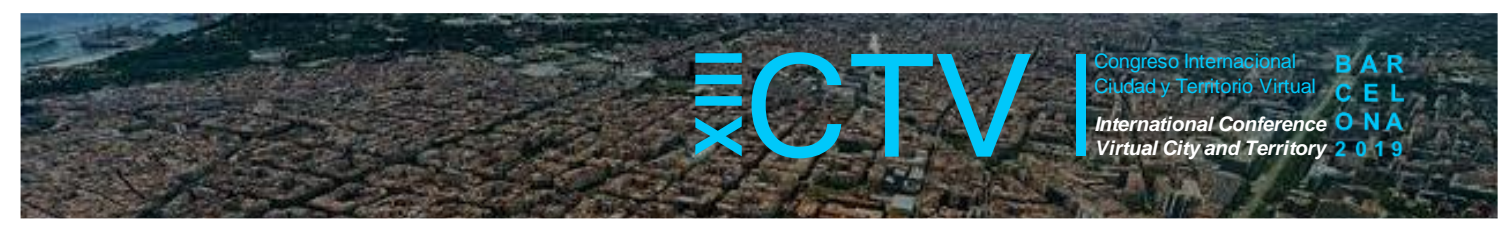

que los bonos suelen pagar un interés fijo durante el período de vencimiento, generalmente se los denomina "valores de renta fija". La finalidad de los bonos verdes es financiar proyectos que contribuyan a la consecución de los Objetivos de Desarrollo Sostenible de la OMS, concretamente el número 7 (energía asequible y no contaminante) y el número 13 (acción por el clima) (Iberdrola, 2019).

\section{Regulación}

La búsqueda de una estandarización en el mercado de bonos verdes y la generación de un esquema tipo de certificación verde, han sido necesidades que se han impulsado en los últimos años por ser parte de los objetivos del Acuerdo de París. Aunque en la actualidad no existe un estándar mundial para la emisión de bonos verdes, existen instituciones como Climate Bond Initiative (CBI) o International Capital Markets Association (ICMA) que utilizan criterios comunes para las certificaciones verdes. Estas certificaciones son Climate Bonds Standard y Green Bond Principles, respectivamente. EI ICMA (2017) se refiere a estos criterios comunes como una guía de transparencia en el proceso, que incorpora cuatro etapas principales: 1) uso de los ingresos, 2) proceso para la evaluación y selección de proyectos, 3) gestión de los ingresos y, 4) informes rutinarios.

\section{Difusión}

El ímpetu por la divulgación de nuevos estándares verdes se ha visto reflejado en la realización de asambleas o convenciones globales como la Cumbre de Acción Climática Global (2018), cuyo principal propósito fue congregar a líderes locales e internacionales de los estados, regiones y ciudades, corporaciones, empresas privadas e instituciones financieras para afianzar los compromisos de acelerar la emisión de bonos verdes y tender a homogeneizar el proceso. Algunos de los participantes comunes en convenciones sobre cambio climático han sido el Grupo Banco Mundial, European Investment Bank, Amundi, Pacto de los alcaldes para el Clima y la Energía, Low Emissions Development Strategies (LEDS), Green Finance Lac (GFL), Climate Bonds, entre otros.

No obstante, aún con un modelo de mercado de bonos verdes no homogeneizado, la emisión de este tipo de créditos crece anualmente; así, mientras que en el año 2007 recién se emitía el primer bono orientado a temas climáticos por el Banco Europeo de Inversiones, para el año 2019 ya se habla de un boom de los bonos verdes debido a su crecimiento exponencial y al interés de inversores y empresas en utilizarlos para financiar proyectos (García, 2019) (World Bank, 2018). Según Bloomberg New Energy Finance (2018), la emisión de bonos verdes a nivel global alcanza la suma de 163,100 millones de dólares (unos 147,000 millones de euros), con una tasa de crecimiento superior al $64 \%$. En este último año, los estadounidenses han encabezado la lista de principales emisores, seguidos por Bélgica y China, cuyas principales áreas de inversión son para eficiencia energética, energías renovables, transporte eficiente y tratamiento de aguas.

En los países de América Latina y el Caribe, si bien no existe una gran participación de bonos verdes, se observa un creciente interés. De acuerdo al Climate Bonds Institute (2018), en el año 2018 se registraron 6,200 millones de dólares en financiamiento con bonos verdes y 20 emisores activos destacados entre países como Brasil y México; este último, realizó la transacción de bonos verdes certificados más grande de la historia para un aeropuerto, que asciende a más de 6,000 millones de dólares y que vence entre el año 2026 y 2047. En la Figura 5 se muestran los territorios con liderazgo en la emisión de bonos verdes certificados y también aquellas que participan en menor proporción, como América Latina. 


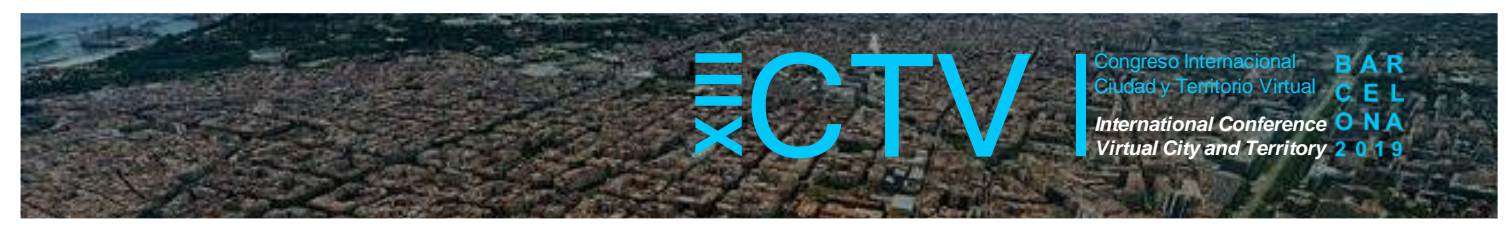

Figura 5. Principales emisores de bonos verdes certificados

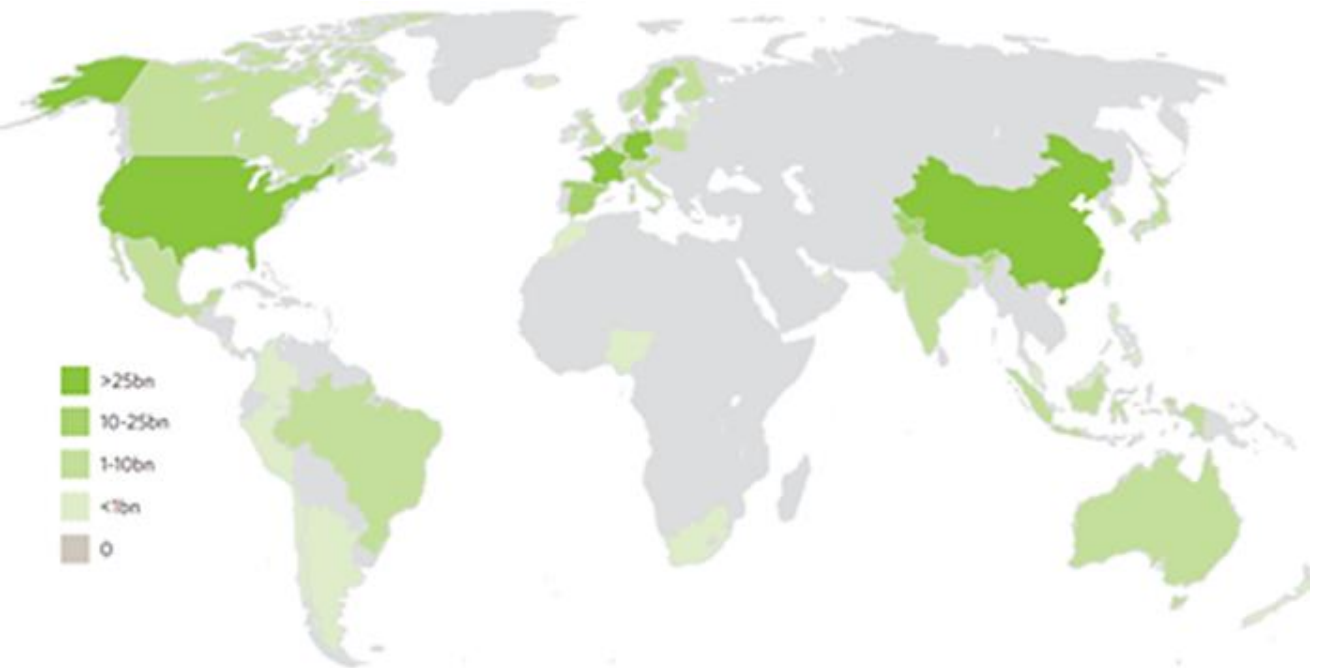

Fuente: CBI Informe de Bonos y Cambio Climático (2018).

\section{Aplicación}

El mercado de los bonos verdes se compone principalmente de tres actores: 1) un emisor, 2) un inversionista y, 3) una Entidad de Propósito Especial (EPE). La emisión de bonos es llevada a cabo por instituciones alineadas al clima, como Estados y compañías mixtas o privadas que requieran implementar proyectos sostenibles, y adquiridos por inversionistas interesados. En cualquiera de los casos, el emisor se compromete a devolver al agente inversor el capital financiado más los intereses pactados ( $y$ en algunos casos acciones del activo adquirido).

El tercer actor del mercado de bonos, denominado Entidad de Propósito Especial (EPE), se incorpora al escenario de compra y venta cuando es necesario un intermediario entre el emisor y el inversor, ya que se encarga de utilizar los activos del emisor como respaldo para emitir una nueva deuda (este proceso se conoce como titulización-bursatilización). Esto es posible ya que, según el ICMA, un proyecto verde puede ser considerado un activo y por ende sus ingresos pueden ser titulizados por una EPE, cuyos recursos pueden usarse para cubrir la deuda de los bonos emitidos. En cuanto a la plataforma de mercadeo, no existe diferencia entre títulos de bonos verdes y bonos convencionales, ya que se encuentran indexados en catálogos bursátiles internacionales sin más distinción que la de su etiqueta verde. No obstante, existen índices de bonos verdes específicos como el Barclays MSCI Global Green Bond Index (2014), que concede a los inversores un entorno más dinámico para la compra de este tipo de títulos, con mayores criterios de selección (como la rentabilidad o TIR) y seguridad financiera (información sobre riesgo de impago, calificaciones crediticias, índices de inflación, entre otros).

Estos factores de selección se dan porque, si bien el objetivo general de un bono verde es financiar proyectos sostenibles, en la actualidad existe una cantidad considerable de esquemas de títulos alineados al cambio climático (Tabla \#3) que se encuentran disponibles en el mercado con diferentes características, modalidades, factores de riesgo y perspectivas a futuro (Programa de Estudios Económicos e Información, 2019). En cuanto a la cantidad de emisión del grupo de los bonos descritos, los bonos supranacionales se destacan sobre los demás debido a que los actores que operan las transacciones son organismos internacionales. Sin embargo, el CBI contabiliza un porcentaje significativo de nuevas modalidades de bonos que conforman el $27 \%$ del total de bonos en el mercado (ver Figura 6). De dicho porcentaje se pueden identificar los 


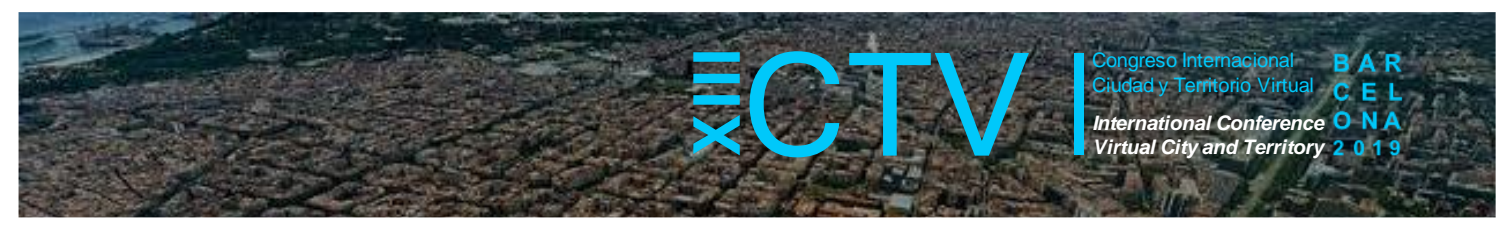

bonos municipales de USA (23\%) conocidos como US Munis (con grandes beneficios fiscales para el inversionista y generalmente emitidos a más largo plazo), los Asset Backed Securities (ABS) con un 18\% de participación; y los Mortgage Backed Securities (MBS), identificados como créditos subprime, con un $36 \%$ de participación en el mercado.

Tabla 3. Tipos de bonos verdes disponibles en el mercado

\begin{tabular}{|c|c|c|c|c|c|}
\hline Tipos de Bonos & $\begin{array}{l}\text { Principal } \\
\text { Emisor * }\end{array}$ & Modalidad & $\begin{array}{l}\text { Destino de los } \\
\text { recursos }\end{array}$ & $\begin{array}{l}\text { Factores } \\
\text { positivos para } \\
\text { Inversionista }\end{array}$ & $\begin{array}{l}\text { Expectativas a } \\
\text { futuro }\end{array}$ \\
\hline $\begin{array}{l}\text { Bono } \\
\text { supranacional, } \\
\text { cuasi - } \\
\text { soberano y de } \\
\text { agencia SSA }\end{array}$ & $\begin{array}{l}\text { Banco } \\
\text { Mundial, } \\
\text { Banco } \\
\text { Europeo de } \\
\text { Inversiones. }\end{array}$ & $\begin{array}{l}\text { Generalmente } \\
\text { se negocia en el } \\
\text { mercado } \\
\text { secundario } \\
\text { (Bolsa de } \\
\text { Valores). }\end{array}$ & $\begin{array}{l}\text { Dirigidos a una } \\
\text { diversa cartera } \\
\text { de proyectos } \\
\text { con atención al } \\
\text { clima. }\end{array}$ & $\begin{array}{l}\text { Alto grado de } \\
\text { inversión (bajo } \\
\text { riesgo). }\end{array}$ & $\begin{array}{l}\text { Margen de } \\
\text { crecimiento medio. } \\
\text { La tendencia de } \\
\text { diversificación de } \\
\text { estructura de bonos } \\
\text { puede aminorar su } \\
\text { crecimiento global. }\end{array}$ \\
\hline $\begin{array}{l}\text { Bonos } \\
\text { Soberanos SSA }\end{array}$ & $\begin{array}{l}\text { Bancos } \\
\text { nacionales, } \\
\text { y/o gobierno. }\end{array}$ & $\begin{array}{l}\text { Generalmente } \\
\text { se negocia en el } \\
\text { mercado } \\
\text { secundario } \\
\text { (Bolsa de } \\
\text { Valores), } \\
\text { aunque pueden } \\
\text { existir } \\
\text { negociaciones } \\
\text { privadas. }\end{array}$ & $\begin{array}{l}\text { Proyectos } \\
\text { verdes en } \\
\text { general. }\end{array}$ & $\begin{array}{l}\text { Alto grado de } \\
\text { inversión (bajo } \\
\text { riesgo). }\end{array}$ & $\begin{array}{l}\text { Margen de } \\
\text { crecimiento alto. La } \\
\text { posible intervención } \\
\text { de otros actores a } \\
\text { nivel local puede ser } \\
\text { una desventaja. }\end{array}$ \\
\hline
\end{tabular}

\begin{tabular}{|c|c|c|c|c|c|}
\hline Bono Municipal & $\begin{array}{l}\text { Principalmente } \\
\text { municipios de } \\
29 \text { estados de } \\
\text { USA }\end{array}$ & $\begin{array}{l}\text { Estos se ofertan } \\
\text { a inversionistas } \\
\text { en el mercado } \\
\text { de valores a } \\
\text { través de casas } \\
\text { de bolsas o } \\
\text { entidades } \\
\text { financieras. }\end{array}$ & $\begin{array}{l}\text { Inversiones en } \\
\text { infraestructura } \\
\text { pública, } \\
\text { proyectos de } \\
\text { transporte, } \\
\text { agua y energía } \\
\text { limpia. }\end{array}$ & $\begin{array}{l}\text { Alto grado de } \\
\text { inversión. } \\
\text { Ofrecen } \\
\text { reducciones de } \\
\text { impuestos a los } \\
\text { compradores } \\
\text { (beneficios } \\
\text { fiscales). }\end{array}$ & $\begin{array}{l}\text { Crecer y ofrecer } \\
\text { oportunidad de } \\
\text { financiamiento para } \\
\text { los proyectos } \\
\text { locales. }\end{array}$ \\
\hline ABS & $\begin{array}{l}\text { Vehículos de } \\
\text { Propósito } \\
\text { Especial } \\
\text { (VPE) } \\
\text { Bursatilización } \\
\text { (en México se } \\
\text { denomina } \\
\text { fideicomiso), } \\
\text { lo lidera USA }\end{array}$ & $\begin{array}{l}\text { Mercados } \\
\text { secundarios. } \\
\text { Bonos } \\
\text { respaldados por } \\
\text { activos } \\
\text { financieros } \\
\text { como el MBS } \\
\text { (Mortgage } \\
\text { Backed } \\
\text { Security), de la } \\
\text { estadounidense } \\
\text { Fannie Mae. }\end{array}$ & $\begin{array}{l}\text { Refinanciar } \\
\text { paneles } \\
\text { solares } \\
\text { residenciales y } \\
\text { comerciales. } \\
\text { Mejora de los } \\
\text { edificios } \\
\text { existentes. }\end{array}$ & $\begin{array}{l}\text { Ofrecen } \\
\text { garantías. } \\
\text { Emisiones de } \\
\text { títulos con } \\
\text { respaldos de } \\
\text { hipotecas de } \\
\text { edificios, } \\
\text { residencia y } \\
\text { activos } \\
\text { comerciales. }\end{array}$ & $\begin{array}{l}\text { Existe un potencial } \\
\text { importante en } \\
\text { Estados Unidos } \\
\text { como incentivo para } \\
\text { la certificación de } \\
\text { edificios. }\end{array}$ \\
\hline Sukuk & $\begin{array}{l}\text { Sector privado } \\
\text { de Malasia e } \\
\text { Indonesia, } \\
\text { respaldado } \\
\text { por el Estado. }\end{array}$ & $\begin{array}{l}\text { El emisor no } \\
\text { paga intereses } \\
\text { al inversor, sino } \\
\text { que entrega } \\
\text { acciones. }\end{array}$ & $\begin{array}{l}\text { Proyectos de } \\
\text { energía solar. }\end{array}$ & $\begin{array}{l}\text { El grupo de } \\
\text { inversionista es } \\
\text { dueño parcial } \\
\text { del activo } \\
\text { financiado. }\end{array}$ & $\begin{array}{l}\text { Medio Oriente } \\
\text { puede optar por } \\
\text { estas estructuras } \\
\text { islámicas para } \\
\text { financiar activos } \\
\text { verdes: bienes } \\
\text { raíces, plantas } \\
\text { solares y } \\
\text { desalinizadoras. }\end{array}$ \\
\hline
\end{tabular}




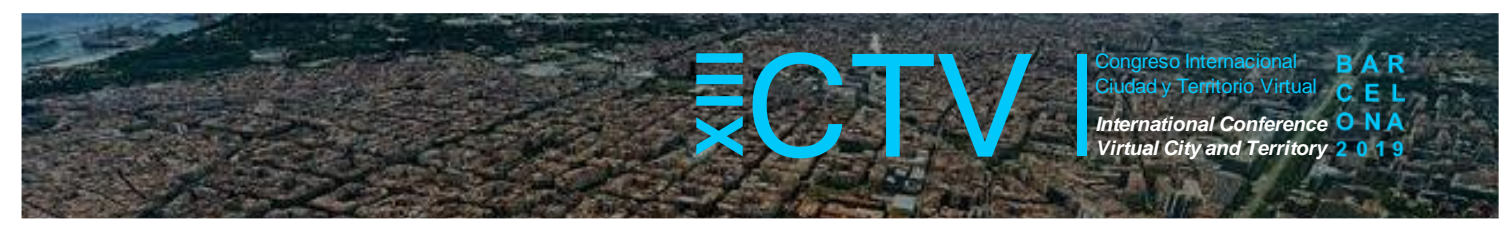

\begin{tabular}{|c|c|c|c|c|c|}
\hline Perpetuos & $\begin{array}{l}\text { Xinjiang } \\
\text { Goodwin } \\
\text { (productor } \\
\text { chino de } \\
\text { turbinas), }\end{array}$ & $\begin{array}{l}\text { No tiene fecha } \\
\text { de vencimiento } \\
\text { y se mantienen } \\
\text { en circulación a } \\
\text { perpetuidad. Sin } \\
\text { embargo, los } \\
\text { emisores fijan } \\
\text { una fecha en la } \\
\text { cual el bono } \\
\text { puede ser } \\
\text { redimido. }\end{array}$ & $\begin{array}{l}\text { Proyectos de } \\
\text { agua, gestión } \\
\text { de aguas } \\
\text { residuales, así } \\
\text { como activos } \\
\text { de energía } \\
\text { renovable. }\end{array}$ & $\begin{array}{l}\text { Pagan un cupón } \\
\text { y posee una } \\
\text { fecha de } \\
\text { reclamación. }\end{array}$ & $\begin{array}{l}\text { Se encuentra en } \\
\text { crecimiento entre } \\
\text { grandes emisores } \\
\text { de Europa. }\end{array}$ \\
\hline $\begin{array}{l}\text { Colocaciones } \\
\text { privadas }\end{array}$ & $\begin{array}{l}\text { Corporaciones } \\
\text { no financieras } \\
\text { y compañías } \\
\text { de recursos } \\
\text { renovables. }\end{array}$ & $\begin{array}{l}\text { El emisor } \\
\text { negocia } \\
\text { directamente } \\
\text { con el } \\
\text { inversionista. }\end{array}$ & $\begin{array}{l}\text { Proyectos del } \\
\text { sector } \\
\text { energético }\end{array}$ & $\begin{array}{l}\text { El plazo y la } \\
\text { divisa de la } \\
\text { negociación son } \\
\text { elegidos por el } \\
\text { inversionista. }\end{array}$ & $\begin{array}{l}\text { Incentivan el } \\
\text { desarrollo de la } \\
\text { introducción de los } \\
\text { bonos verdes en } \\
\text { mercados } \\
\text { emergentes. }\end{array}$ \\
\hline Garantizados & $\begin{array}{l}\text { Instituciones } \\
\text { financieras } \\
\text { alemanas, } \\
\text { noruegas y } \\
\text { suecas. }\end{array}$ & $\begin{array}{l}\text { Estructura dual: } \\
\text { El inversionista } \\
\text { tiene un recurso } \\
\text { general contra } \\
\text { el emisor, así } \\
\text { como sobre un } \\
\text { grupo de activos } \\
\text { de garantía. }\end{array}$ & $\begin{array}{l}\text { Proyectos de } \\
\text { energía } \\
\text { renovable. }\end{array}$ & $\begin{array}{l}\text { Calificaciones } \\
\text { crediticias } \\
\text { superiores (bajo } \\
\text { riesgo), el } \\
\text { inversor está } \\
\text { garantizado. }\end{array}$ & $\begin{array}{l}\text { Tienen desarrollo a } \\
\text { futuro si se } \\
\text { establece } \\
\text { legislaciones para la } \\
\text { emisión de bonos de } \\
\text { recurso dual. }\end{array}$ \\
\hline Schuldschein & $\begin{array}{l}\text { Lo lidera } \\
\text { Alemania, a } \\
\text { través de } \\
\text { empresas de } \\
\text { energía eólica } \\
\text { e } \\
\text { inmobiliarias. } \\
\text { Le siguen } \\
\text { España, } \\
\text { Francia y } \\
\text { Países Bajos. }\end{array}$ & $\begin{array}{l}\text { El emisor } \\
\text { negocia } \\
\text { directamente } \\
\text { con el } \\
\text { inversionista de } \\
\text { manera privada. }\end{array}$ & $\begin{array}{l}\text { Proyectos } \\
\text { eólicos e } \\
\text { inmobiliarios. }\end{array}$ & $\begin{array}{l}\text { Formato } \\
\text { establecido de } \\
\text { deuda (notas de } \\
\text { préstamos } \\
\text { bilaterales). }\end{array}$ & $\begin{array}{l}\text { Los bonos } \\
\text { mantendrán su } \\
\text { atractivo entre los } \\
\text { sectores } \\
\text { corporativos y } \\
\text { financieros dado el } \\
\text { formato establecido } \\
\text { de deuda y su } \\
\text { flexibilidad. }\end{array}$ \\
\hline
\end{tabular}

Fuente: Elaboración propia con datos de CBI Informe de Bonos y Cambio climático (2018).

*El resumen incorpora los principales emisores que han sido identificados por el CBI.

Figura 6. Proporción de nuevos bonos aplicados según CBI

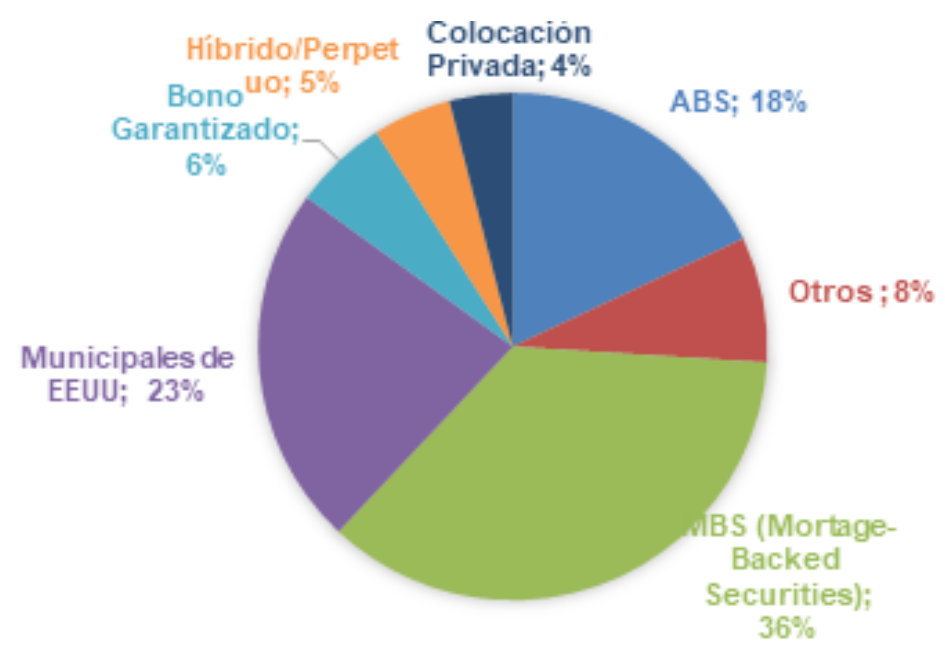

Fuente: CBI Informe de Bonos y Cambio climático (2018). 


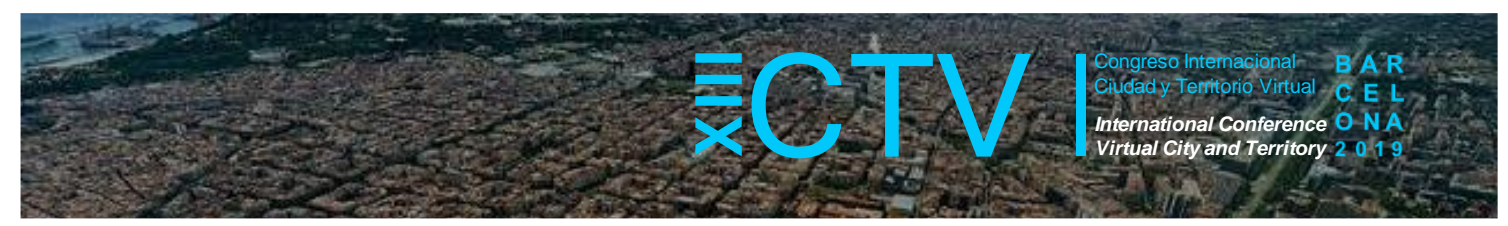

Respecto a esta diversificación de bonos verdes, Anderson (2019) afirma que, si bien la intermediación financiera tradicionalmente ha involucrado a los bancos como agentes que toman los depósitos y hacen préstamos a empresas y consumidores, los nuevos procesos de intermediación se están basando en que los bancos también piden prestado dinero, realizan titulaciones de préstamos y compran y venden valores en el mercado abierto (ABS). No obstante, aunque parezca que la variedad de bonos verdes promueve su crecimiento en el mercado, López et al., (2009) afirman que la gran cantidad de intermediarios financieros también pone en peligro la estabilidad de los mercados, puesto que las innovaciones en la creación y negociación de los productos derivados y, más concretamente de los productos estructurados, pueden propiciar un crecimiento desmedido de alto riesgo.

Según el CBI (2018), los sectores más beneficiados con la emisión de bonos han sido las empresas de energía y la edificación de consumo casi nulo, siendo este último el más dinámico puesto que presenta menores plazos de inversión. En el 2018, de toda la inversión alineada al cambio climático, más del $97 \%$ de los bonos verdes etiquetados (aproximadamente 70,000 millones de dólares) fue usado para financiar propiedades certificadas y para proyectos de eficiencia energética en edificios. Este importe es de gran valor estratégico en el contexto del cambio climático, puesto que la creciente descarbonización de la industria de la construcción comercial y residencial representa una disminución importante en la emisión global de gases de efecto invernadero (GEI).

En cuanto a las ventajas financieras, la literatura especializada ha estudiado los beneficios del uso de bonos verdes en el mercado financiero y las ventajas que repercuten en los actores involucrados; así como también los incentivos comerciales que se deben producir para afianzar su crecimiento. Desde el punto de vista del emisor, Gianfrate y Peri (2019) concluyen que los bonos verdes son más convenientes que los bonos convencionales puesto que, como se ha adoptado un enfoque de propensión a la calificación y evaluación de proyectos, esto representa un entorno financiero transparente y una forma efectiva de lograr llamar la atención de instituciones inversoras que requieran financiar proyectos ecológicos con diferentes aportes de capital y tasas de riesgo definidas.

Si bien las ventajas respecto a la seguridad financiera del emisor lo son también para el inversionista, el beneficio efectivo de este último se ha de ver reflejado en las condiciones y garantías en las cuales retorna su capital de inversión (Lam y Law, 2018). En ese sentido, Mclnerney y Bunn (2019) analizan que, aún con el desarrollo de calificaciones crediticias y el progreso en la confiabilidad de inversión en bonos verdes, todavía no se han logrado afianzar las iniciativas de políticas gubernamentales y beneficios fiscales a nivel local para que las instituciones de inversión manifiesten un interés sólido y lucrativo en un mercado global cada vez más inclinado a la transición energética.

Finalmente, aunque los beneficios estimados para los emisores e inversores se han estudiado de manera global, es imprescindible establecer las diferencias de estos beneficios financieros en los países desarrollados en contraposición con los países en vías de desarrollo y/o mercados emergentes. Banga (2019) identifica que las principales barreras de emisión de bonos verdes en países en vías de desarrollo están relacionadas a la falta de acuerdos institucionales para su gestión y los altos costos de transacción asociados a su emisión. Se reconoce que es necesario el impulso proveniente de organismos multilaterales que proporcionen garantías a los emisores y que cubran los costos de transacción asociados a dicha emisión. 


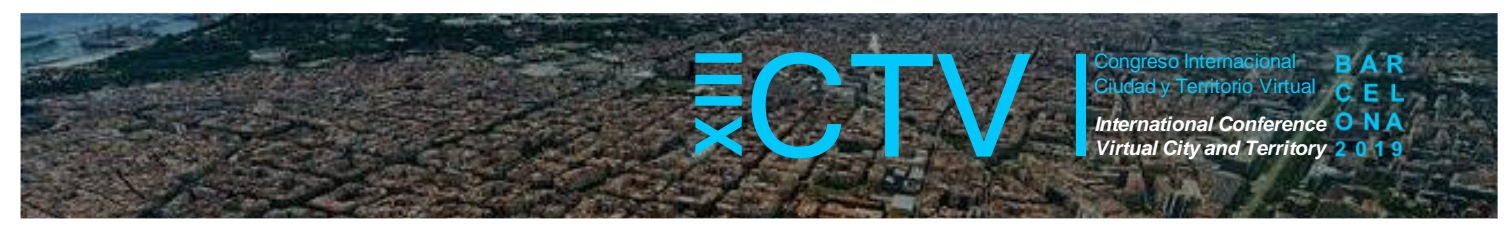

\subsection{Hipotecas verdes}

El Green Building Council España (GBCe) revela que las hipotecas representan alrededor de un tercio de los activos del sector bancario europeo, equivalentes a la mitad del PIB de la UE (7 billones de euros al final del 2016), lo cual muestra la potencialidad que tendría convertir en verde este sector. Las hipotecas verdes o de eficiencia energética (EEM, por sus siglas en inglés), son aquellos préstamos hipotecarios vinculan el tipo de interés hipotecario con la eficiencia energética, de alguna manera. La idea fundamental es ofrecer beneficios económicos a los acreedores, para la compra o reforma de una vivienda.

El reto es hacer que las EEM sean competitivas tanto para el sector bancario como para los posibles consumidores de este tipo de hipoteca. A continuación, se analiza el panorama en diferentes países, en cuanto a la regulación, difusión y aplicación de la hipoteca verde en cada uno de ellos.

\subsubsection{Hipotecas verdes en Estados Unidos}

Las EEM actualmente están financiadas por tres entidades: Fannie Mae, Freddie Mac y la Federal Housing Administration (FHA), que son en su totalidad entidades promovidas por el Gobierno Federal de los USA Este esquema de financiamiento verde tuvo origen en 1980, cuando el presidente Jimmy Carter firmó una orden ejecutiva que regulariza las instituciones del mercado secundario que ofrecían incentivos crediticios a los consumidores de viviendas de eficiencia energética. En 1981 se estableció un sistema de medición de la eficiencia energética mediante la creación del National Shelter Industry Energy Advisory Council, procedimiento que dio paso a la ejecución de pruebas piloto de hipotecas de eficiencia energética entre 1992 y 1995 , hasta llegar a la actual configuración de EEM.

En cuanto a las condiciones del programa hipotecario, desde junio de 2006, el Departamento de Vivienda y Desarrollo Urbano de EE. UU (HUD, por sus siglas en inglés) anunció que la cantidad máxima de préstamo del paquete energético no será superior al $5 \%$ de: 1) el valor de la propiedad, 2) el $115 \%$ del precio de una vivienda unifamiliar de área mediana, 3) el $150 \%$ del límite del préstamo Freddie Mac establecido por la HUD en junio de 2006 (625,500 dólares), condiciones que se mantienen hasta la actualidad.

\section{Regulación}

Estados Unidos, a diferencia de los países de la Unión Europea, no tiene un sistema de etiquetado energético obligatorio. Sin embargo, existen regulaciones sobre los mínimos de eficiencia energética con los que deben cumplir las edificaciones. Para realizar estas regularizaciones Estados Unidos tiene dos entidades gubernamentales que trabajan en conjunto, que son el Departamento de Vivienda y Desarrollo Urbano (HUD, por sus siglas en inglés) y el Departamento de Energía de los Estados Unidos (DOE, por sus siglas en inglés). El producto final, la hipoteca, es el resultado de una colaboración entre asociaciones públicas y privadas (ver Figura 7). Las EEM se basan en que, si los gastos relacionados con la energía se ven reducidos, los dueños pueden utilizar este ahorro para invertir en una mayor eficiencia energética.

Estados Unidos, a diferencia de los países de la Unión Europea, no tiene un sistema de etiquetado energético obligatorio. Sin embargo, existen regulaciones sobre los mínimos de eficiencia energética con los que deben cumplir las edificaciones. 


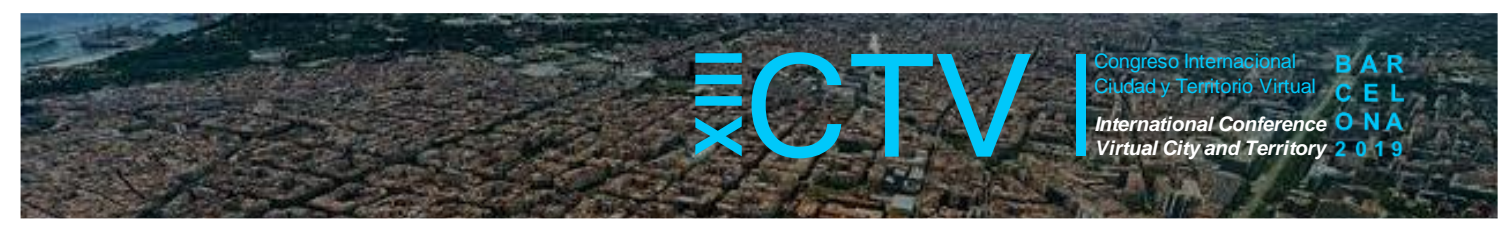

Figura 7. Proceso de financiamiento de hipotecas verdes en Estados Unidos
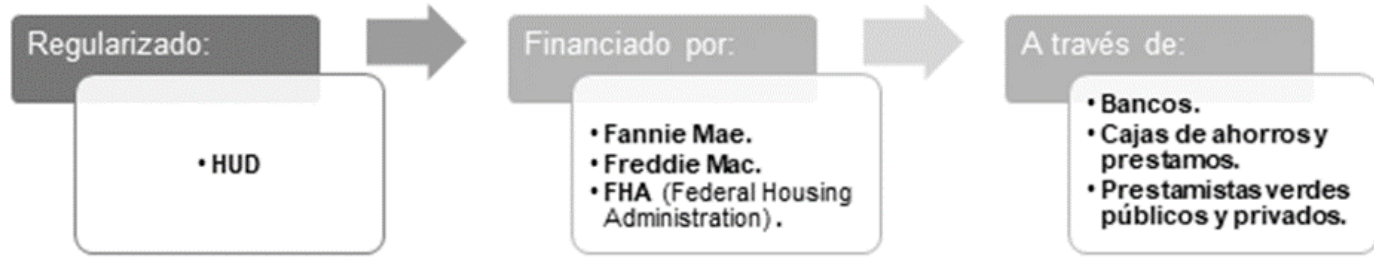

Fuente: Elaboración de los autores con datos de la FHA (2018).

\section{Difusión}

La hipoteca verde presentada por la HUD junto a la FHA permite acceder a un Energy Package, que es un conjunto de mejoras realizadas en una vivienda no eficiente energéticamente, adquirida con la hipoteca estas mejoras son basadas en las recomendaciones y análisis realizados por un asesor cualificado. Existen dos categorías de hipoteca: 1) Cost Effective Test for Newly Constructed Homes, utilizada para comprar casas nuevas que cumplen con los estándares de eficiencia energética y 2) Cost Effective Test for Existing Homes, que se utilizan para proporcionar mejoras de eficiencia energética a los hogares existentes. Esta hipoteca permite acceder a un préstamo no mayor al monto establecido por la HUD.

De igual forma existen otro tipo de hipotecas verdes más convencionales, ofrecidas por prestamistas que venden los préstamos realizados a Fannie Mae y Freddie Mac, como una hipoteca de eficiencia energética que permite acceder a un préstamo hasta el $15 \%$ del valor de tasación de la vivienda para mejoras. También, se encuentran hipotecas de eficiencia energética del Departamento de Asuntos de los Veteranos de los Estados Unidos (VA, por sus siglas en inglés), para veteranos calificados y personal militar donde; parte de compra/mejora de vivienda son $\$ 6000$ adicionales para mejoras de eficiencia energética, si el ahorro de energía proyectado supera el aumento resultante de los pagos de la hipoteca y $\$ 3000$ basado únicamente en el costo documentado de las mejoras

\section{¿Cómo solicitar un préstamo hipotecario verde en Estados Unidos?}

Bank of America es uno de los principales bancos en Estados Unidos según la lista de setiembre del 2018 del Consejo de Examen de Instituciones Financieras Federales (FFIEC, por sus siglas en inglés), el cual incluye en sus webs varios estudios sobre cómo la eficiencia energética tiene impacto en la venta y los valores de las viviendas. "Las casas con certificación ENERGY STAR en ciertos condados de Washington y Idaho tenían precios de venta más altos que las casas que no estaban certificadas" (Earth Advantage Institute, 2015).

En la orientación que nos da para obtener una EEM, indica que el primer paso es contactar un contratista certificado como el Building Performance Institute (BPI), principal organización en los Estados Unidos de credenciales y auditoría de energía residencial; segundo paso cumplir con una calificación; tercer paso adquirir la certificación. Finalmente, al obtener la Certificación, el banco ofrece una línea de crédito con garantía hipotecaria, a menudo llamada HELOC, la cual permite obtener préstamos contra el valor de la propiedad en el momento de solicitar la hipoteca. Una HELOC es una herramienta de financiamiento verde flexible que se puede utilizar para comprar o realizar mejoras en la vivienda, por lo general tiene una tasa de interés ajustable. la mayoría de las Instituciones financieras entregan cheques o una tarjeta de crédito, y se puede tomar prestado dinero por un cierto tiempo a partir del momento en que se abra la cuenta, este periodo de tiempo se le conoce como el "periodo de disponibilidad del préstamo" (ver Figura 8). 


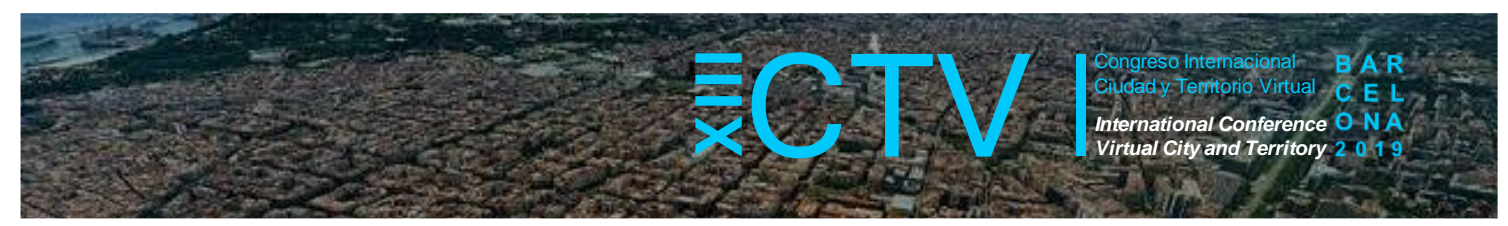

Figura 8. Pasos para solicitar una hipoteca verde en Estados Unidos

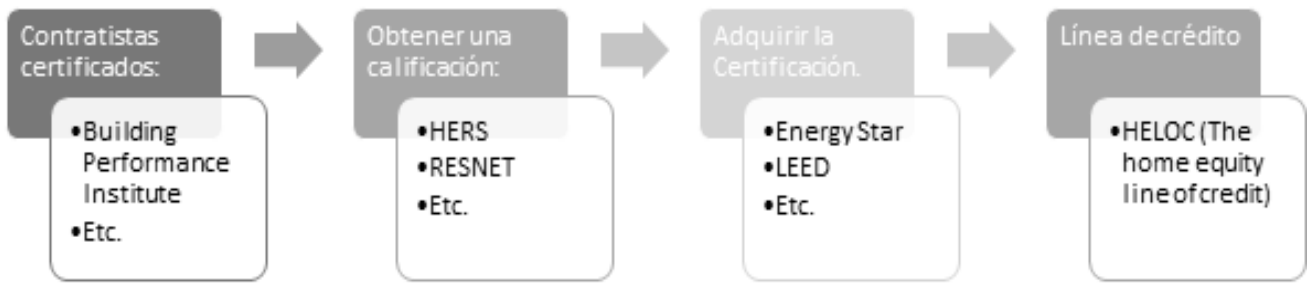

Fuente: Elaboración Propia con datos del Bank Of America

La cantidad que se podría solicitar depende del valor estimado de la vivienda y de si se tiene algún tipo de deuda hipotecaria pendiente (existe la posibilidad de utilizar una parte del patrimonio de la vivienda). El proceso concluiría con la validación y financiamiento de un responsable de una de las tres empresas que monopolizan los programas hipotecarios de Eficiencia Energética en USA: Fannie Mae, Freddie Mac y FHA.

\subsubsection{Hipotecas verdes en México}

Inspirado en los principios del Desarrollo Sostenible, en el 2007 el gobierno mexicano se planteó, entre otros objetivos, impulsar un desarrollo habitacional sostenible. En ese sentido, el INFONAVIT (2019), institución creada por Ley y derivada de la Constitución Política de principios del siglo XX, impulsó el financiamiento de viviendas mediante hipotecas verdes, empezando como un programa piloto. El programa de Energy Efficient Mortgages (EEM) del INFONAVIT consiste en otorgar un monto adicional al crédito para que el acreedor adquiera una vivienda nueva, mejore o amplíe la existente, y la equipe con tecnologías amigables con el medio ambiente (ecotecnologías), las cuales deben ser reconocidas por la institución. Desde el 2007 al 2009 el programa estuvo enfocado a trabajadores de bajos ingresos con un ingreso de hasta cuatro veces el salario mínimo. Para el 2009 , la cobertura del programa de EEM ya se extendía por todo el territorio mexicano, siendo considerada una de las iniciativas más exitosas a nivel mundial desde la perspectiva de la cobertura. La demanda se ha expandido aún más desde el 2011, año en el que el programa verde pasó a ser obligatorio para toda hipoteca obtenida por medio del INFONAVIT. Desde el punto de vista de las ecotecnologías, hasta el 2011, las posibilidades de acceder a una hipoteca verde tenían forma de paquetes fijos organizados según la zona climática. No obstante, a partir de 2011 se estableció lo que se denomina la Hipoteca Verde Flexible que, aunque obligatoria, contiene la opción de elegir las ecotecnologías según sean requeridas.

\section{Regulación}

Actualmente, todos los créditos que otorga el INFONAVIT cuentan con hipoteca verde, lo que significa que todas las viviendas financiadas comprenden la incorporación de ecotecnologías, las cuales deben cumplir los siguientes requisitos:

La vivienda debe incorporar una combinación de ecotecnologías especificadas en el Manual Explicativo del Programa; como accesorios ahorradores de agua, luz y gas.

- Las ecotecnologías que se agreguen pueden ser elegidas entre aquellas que hayan sido validadas de acuerdo con los ahorros medidos por una entidad independiente reconocida, teniendo que generar un ahorro de entre 4.49 a 17.98 euros mensuales, dependiendo de la localidad y el clima donde se ubique la vivienda.

- Las ecotecnologías que se incorporen deben garantizar un ahorro mínimo progresivo sujeto al nivel de ingreso del trabajador (ver Tabla 4), el monto de crédito ha de formar parte de manera automática del crédito hipotecario. 


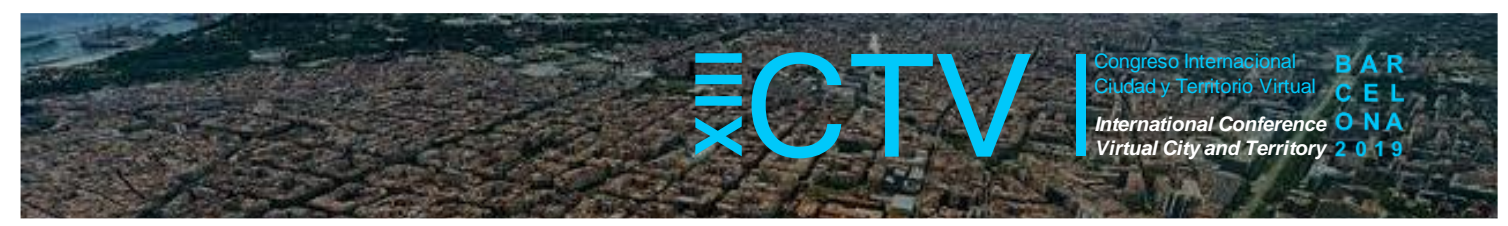

Tabla 4. Ingreso mensual y monto adicional Hipoteca Verde

\begin{tabular}{ccc}
\hline Ingreso mensual (US\$) & Crédito adicional (US\$) & Ahorro mínimo mensual (US\$) \\
\hline 144 a 230 & 288 & 7 \\
\hline 230 a 576 & 1440 & 15 \\
\hline 576 a 1008 & 1440 & 17 \\
\hline 1008 a 1584 & 2160 & 20 \\
\hline 1584 en adelante & 2880 & 27 \\
\hline
\end{tabular}

Fuente: INFONAVIT (2019).

Las ecotecnologías que están dentro del programa de hipoteca verde deben cumplir con ciertos criterios, los cuales son validados mediante el cumplimiento de la normatividad mexicana vigente (Normas Oficiales Mexicanas y Normas Mexicanas), a través de certificados emitidos por los Organismos Normalizadores y Certificadores (Organismo Nacional de Normalización y Certificación de la Construcción y Edificación, Asociación Nacional de Normalización y Certificación del Sector Eléctrico, Centro de Normalización y Certificación de Producto y Sociedad Mexicana de Normalización y Certificación). En estos se especifica tanto el nivel de eficiencia con el que cuentan los productos por arriba de los estándares mínimos nacionales, así como las especificaciones de garantía y vida útil.

\section{Difusión}

El sistema de financiamiento del INFONAVIT es tripartito: patronal, ejecutivo federal y laboral. Este último se materializa en un descuento legal en la nómina de cada trabajador, que asciende al $5 \%$ del sueldo. La participación de este fondo en el ámbito de la vivienda respecto al universo de los créditos hipotecarios es sumamente alta. Según datos del propio Instituto, los créditos INFONAVIT llegan al $69 \%$ del total de los créditos a nivel nacional y sus beneficiarios son, en un $79 \%$, trabajadores con sueldos por debajo de los 4 salarios mínimos (aproximadamente 10,144 pesos mexicanos equivalente a 455.92 euros).

El prestatario de las EEM tiene dos opciones en la selección:

- Vivienda Nueva: En este caso el dueño de la vivienda es el responsable de seleccionar las tecnologías de agua y energía que cumplan con los ahorros mínimos que indica el programa para que la vivienda acceda al crédito, todas las ecotecnologías deben cumplir con las normas ya establecidas.

- Vivienda existente, ampliación, reparación o construcción propia, el acreedor es el encargado de seleccionar las tecnologías que cumplan con el ahorro mínimo establecido.

Si la vivienda nueva o existente no cuenta con dispositivos eco tecnológicos, el prestatario ha de acceder a un monto adicional en función del ahorro que se puede alcanzar mediante la incorporación de tecnologías de ahorro. Dicho monto adicional se debe canjear con un proveedor autorizado por el propio INFONAVIT, quien las instalará en la vivienda una vez que se haya realizado el crédito hipotecario. Así, el INFONAVIT liquida al vendedor de la vivienda el precio de esta, y al proveedor acreditado el monto correspondiente a las ecotecnologías instaladas. En caso de que se pida el crédito para construir en terreno propio, reparar o ampliar la vivienda, se ha de asegurar que se instalen las ecotecnologías que cumplan con el ahorro mínimo esperado conforme a una tabla de ahorro, teniendo que adquirirlas con cualquiera de los proveedores autorizados por el INFONAVIT. En este caso, el monto de crédito adicional que otorga el INFONAVIT forma parte del crédito hipotecario y el pago de las ecotecnologías se hace directamente a los proveedores que se haya seleccionado. 


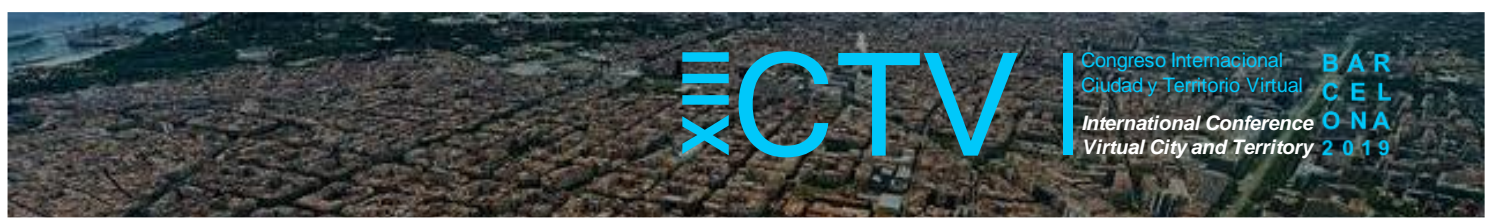

¿Cómo solicitar un préstamo hipotecario verde en México?

Para solicitar un EEM, INFONAVIT dispone un simulador de hipoteca verde para vivienda nueva o usada, puede ser una vivienda independiente o un departamento en un edificio, que permite realizar un rápido cálculo del monto aproximado del crédito hipotecario.

El simulador está desarrollado en dos partes. La primera de ellas (ver Figura 9) apunta a determinar, según la localización geográfica de la vivienda e ingreso del beneficiario, el monto de ahorro al que se debería llegar post elección de un cierto grupo de dispositivos o sistemas de sustentabilidad habitacional. En la segunda parte (ver Figura 10) aparecen los cuadros de individualización de ecotecnologías, donde se comienza por las que permiten grandes ahorros como paneles fotovoltaicos $u$ otras similares, y se termina con las que se denominan "otras tecnologías", donde se encuentran, por ejemplo, aparatos de línea blanca. Una vez que se seleccionan las ecotecnologías disponibles, el simulador calcula el ahorro mensual programado.

Se realizó un ejercicio dentro del portal, lo cual nos permite analizar qué tan factible es acceder a un préstamo. En la primera ventana se llenó el apartado del salario mensual, ya que el programa va dirigido a trabajadores de bajos ingresos, colocando el salario mínimo mensual que es aproximadamente 113.98 euros (2,536 pesos mexicanos), según la Comisión Nacional de los Salarios Mínimos (CONASAMI); en el siguiente apartado se colocó la edad de 29 años, el cual nos permite cumplir con el plazo de amortización que usualmente es entre 30 y 40 años para el préstamo de una vivienda. Como resultado se obtiene un Ahorro mínimo mensual a cumplir de 4.49 euros (100 pesos mexicanos), y un monto aproximado para la compra e instalación de las ecotecnologías de 206.29 euros (4589.79 pesos mexicanos). Al terminar este proceso se despliega una segunda ventana donde se deben indicar las ecotecnologías con que contará la vivienda, teniendo en cuenta que la suma de los ahorros elegidos debe exceder el ahorro mínimo mensual calculado para poder acceder a un préstamo hipotecario.

Es importante señalar que en todo el proceso de simulación no existe mayor información de las denominadas tecnologías aparte del ahorro que ellas suponen según las tablas que se han completado.

Figura 9. Cuadro para la definición de montos requeridos de ahorro mensual

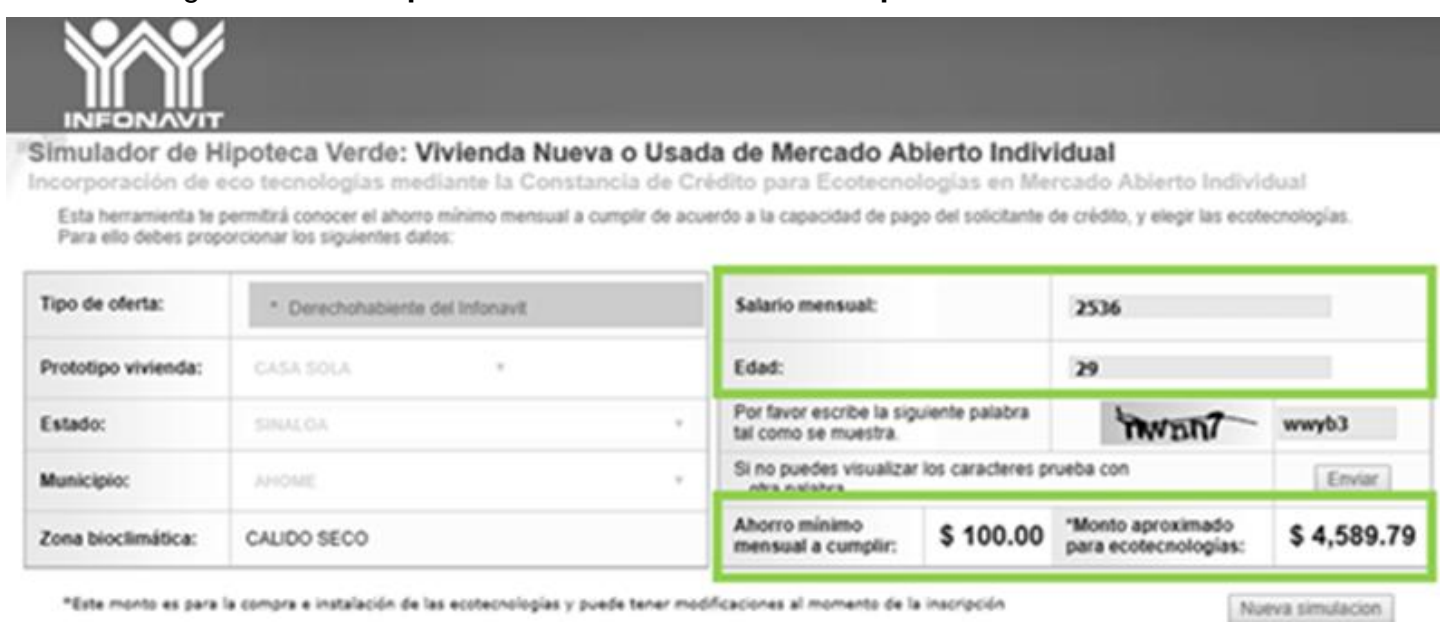

Fuente: Elaboración de los autores con datos recuperados del simulador INFONAVIT. 


\section{Figura 10. Selección de ecotecnologías}

\begin{tabular}{|c|c|c|}
\hline \multicolumn{3}{|c|}{ OPCION DE AHORRO MÁXXIMO } \\
\hline Tipo & Selecciona tu ecotecnologia & $\begin{array}{l}\text { Ahorro } \\
\text { Mensual }\end{array}$ \\
\hline Ahorrador de energla electrica & Optimizador de tensión eléctrica de 20-39(Ahorro desde 27-08-14) & - \\
\hline Are acondicionado & $\begin{array}{l}\text { Un equipo de aire acondicionado de atta eficiencia o de baja consumo } \\
\text { de } 1 \text { th (Ahorro desde } 27-08-14 \text { ) }\end{array}$ & - \\
\hline Pancles fotovoltaicos & $\begin{array}{l}\text { Sistema Fotovoltaico para la vivienda, interconectado a Red, de } 250 \\
\text { Watts (Ahorro desde 03-09-2015) }\end{array}$ & - \\
\hline Calentador & $\begin{array}{l}\text { Calentador solar de agua plano con respaldo de calentador de gas de } \\
\text { paso con capacidad de } 4.0 \mathrm{a} 6.5 \mathrm{ks} / \mathrm{min} \text {. }\end{array}$ & - \\
\hline \multicolumn{3}{|c|}{ LINEA DE BASE DE EACIENCIAY AMBENTAL. } \\
\hline Tipo & Selecciona tu ecotecnologia & $\begin{array}{l}\text { Ahorro } \\
\text { Mensual }\end{array}$ \\
\hline Inodoro & Dos inodoros de grado ecolbgico máximo 5 litros & - \\
\hline Regadera & Dos regaderas grado ecologico con dispositivo ahorrador integrado & - \\
\hline Set de llaves lawabo de baho & $\begin{array}{l}\text { Tres sets de Llaves (valmulas) con dispositivo ahorrador de agua en } \\
\text { lavabos de baño }\end{array}$ & - \\
\hline Set de liaves de cocina & Dispostivo ahorrador de flujo de agua en lave de cocina & - \\
\hline Váwula regiladora & Vâlvula reguladora, para flujo de agua, en tuberia de suministro & - \\
\hline Focos ahorradores & 8 LED (Ahorro desde 09-07-2015) & - \\
\hline Calentador de Gas & $\begin{array}{l}\text { Calentador de gas de paso Rápida Recuperación con capacidad de } 9.1 \\
\text { a } 12 \text { ts } / \mathrm{min} \text {. }\end{array}$ & - \\
\hline $\begin{array}{l}\text { Aislante termico en techos Recubaimento } \\
\text { reflectwo en techos }\end{array}$ & Recubrimiento reflectivo como acabado final en el techo hasta $45 \mathrm{~m} 2$ & - \\
\hline \multicolumn{3}{|c|}{ OTRAS ECOTECNOLOGIAS } \\
\hline Tipo & Selecciona tu ecotecnologia & $\begin{array}{l}\text { Ahorro } \\
\text { Mensual }\end{array}$ \\
\hline Refingerodor & Refrigerador de 9 a 12 pies (Ahorro desde 09-06-2015) & \multirow{5}{*}{$\begin{array}{l}\text { La suma } \\
\text { debe } \\
\text { exceder el } \\
\text { Ahorro } \\
\text { minimo } \\
\text { mensual ya } \\
\text { calculado } \\
\text { para poder } \\
\text { acceder a } \\
\text { un } \\
\text { préstamo } \\
\text { hipotecario }\end{array}$} \\
\hline Lavadora & $\begin{array}{l}\text { Lavadora grado ecologico con una eficiencia de } 0.27 \text { (Ahorro desde } 09 . \\
06-2015 \text { ) }\end{array}$ & \\
\hline Estufa & Estufa de 30 pies (Ahorro desde 09-06-2015) & \\
\hline $\begin{array}{l}\text { Asslante termico en murosiRecubrimiento } \\
\text { reflectivo en muros }\end{array}$ & Recubrimiento reflectivo como acabado final en muro hasta $20 \mathrm{~m} 2$ & \\
\hline Captación de agua & $\begin{array}{l}\text { Sistema de Captación de agua pluvial, de dos módulos (Ahorro desde } \\
\text { 03-09-2015) }\end{array}$ & \\
\hline Ventanas & Ventanas con doble acristalamiento de más de $8.00 \mathrm{~m} 2$ & -1 \\
\hline
\end{tabular}

Fuente: Elaboración de los autores con datos recuperados del simulador INFONAVIT.

\subsubsection{Hipotecas verdes en la Unión Europea}

La Comisión Europea mantiene un importante interés en investigar la viabilidad de incorporar criterios de sostenibilidad en el mercado financiero europeo. La Unión Europea ha formado un consorcio nacional con la European Mortgage Federation (EMF), que establece la EEM como una herramienta financiera verde importante para combatir el cambio climático, a través de un Plan de Acción de Financiación Sostenible, lleva a cabo un programa llamado EEMI (Energy 


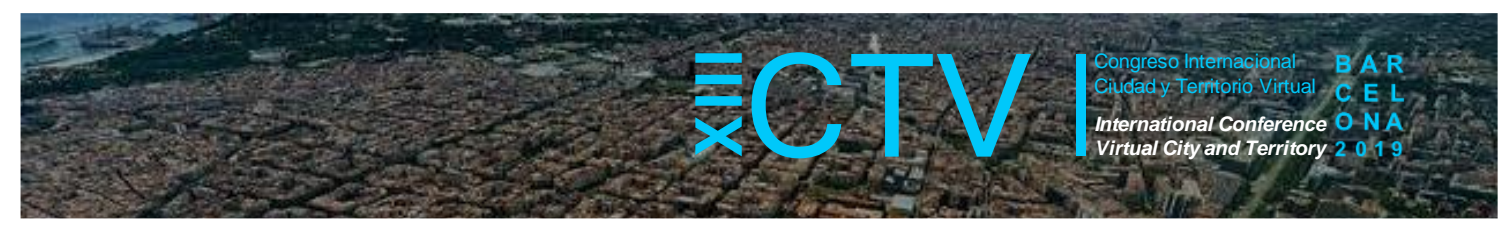

Efficient Mortgages Initiative), que se desarrolla en dos líneas: Energy Efficient Mortgages Action Plan (EeMap) y Energy Efficiency Data Protocol and Portal (EeDaPP). La base de estos programas tiene por objetivo incentivar la participación del capital privado en inversiones de eficiencia energética, asumiendo que:

- Mejorando la eficiencia energética de una propiedad, hay un impacto positivo en el valor de esta, reduciendo el riesgo del producto bancario.

- Los consumidores de estos productos tienen menos probabilidades de impago de la hipoteca, dado que su gasto en energía es menor, reduciendo el riesgo del banco y de los compradores de las titulizaciones.

En la iniciativa participan 37 entidades financieras en toda Europa y 23 organizaciones del sector inmobiliario, quienes gestionan el $45 \%$ de las hipotecas del continente.

\section{Regulación}

El certificado de eficiencia energética es esencial para solicitar una EEM. Más allá de ser una garantía para posibles compradores o inquilinos (porque permite tener más información del estado de la vivienda), es un documento fundamental para aprobar el financiamiento y acceder a los descuentos. Para acceder al certificado, se debe contactar con un técnico certificado, el cual hará un análisis de la vivienda, donde tomará en cuenta los materiales de cerramiento exterior, carpintería (tipo de ventanas), sistema de climatización, entre otras cosas.

Luego hará un informe de calificación energética donde evaluará desde "A" hasta la letra "G" según el grado de consumo energético de la vivienda. Además, tendrá que redactar un dossier en el que debe figurar propuestas de mejora para la vivienda y así elevar su calificación energética. De este modo, las viviendas con una puntuación mayor (letra $A+$ ), son a las que tienen más bajo interés; mientras que para las de baja puntuación (letra G) tienen un tipo de interés mayor. No obstante, en las hipotecas verdes se consideran también las condiciones del mercado, es decir, la viabilidad económica y la competitividad.

\section{Difusión}

El Plan de Acción de Financiación Sostenible establece una serie de recomendaciones para la creación de un producto hipotecario a medida que beneficie el uso eficiente de la energía en los edificios europeos. En el cual se desarrolla los mecanismos de financiamiento hipotecario de EeMAP, que está diseñado para ser respaldado por un protocolo de datos y un portal, entregados por la Iniciativa EeDaPP, para recopilar y acceder a evidencia empírica a gran escala relacionada con los activos hipotecarios de eficiencia energética que permite un análisis exhaustivo de las características de eficiencia energética sin riesgos. (EeMAP, 2018)

\section{EeMAP}

El proyecto EeMAP tiene como objetivo la creación y promoción de hipotecas vinculadas con la eficiencia energética, específicamente a la calificación de la vivienda y con condiciones favorables para el solicitante de la hipoteca. Las prioridades políticas de la propuesta incluyen la mayor inversión, el aumento de actividad del sector, creación de nuevos puestos de trabajo y el estudio de aumento de beneficios para los bancos e inversores (EeMAP, 2018).

La iniciativa también está relacionada a una serie de prioridades políticas: 1) Energy Efficiency, que promueve una mayor inversión en edificios con eficiencia energética, 2) Jobs y Growth, que busca inversión privada en mejoras de eficiencia energética de la vivienda, aumentando la actividad del sector de mejoras energéticas y creando nuevos puestos de trabajo y, 3) Financial 


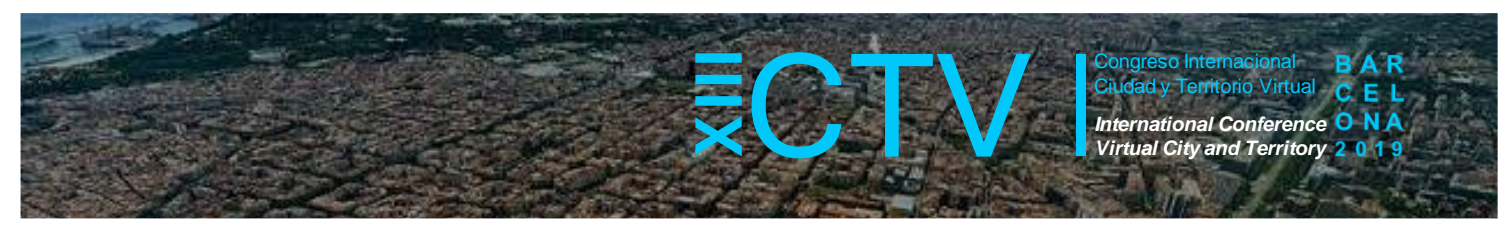

Stability, relacionado a la creación de beneficios para los que prestan y otorgan hipotecas verdes y para los inversores de la iniciativa.

EeDaPP

El proyecto EeDaPP tiene como propósito diseñar y llevar a cabo un protocolo de recopilación de datos relacionados a EEM a gran escala y así poder desarrollar un verdadero mercado de eficiencia energética con base en un modelo estandarizado de hipotecas.

La recolección y análisis de los datos inició en el año 2018. La iniciativa fue utilizada también para asegurar un diseño de hipoteca competente y energéticamente eficiente. Se planteó que EeDaPP, con el tiempo, sea accesible por medio de un portal común y centralizado, facilitando la asignación de activos para la emisión de bonos verdes. La parte significativa de su diseño recae en el diseño de un protocolo y un portal paneuropeo de datos de eficiencia energética, el cual se está desarrollando como consultas intersectoriales con los principales interesados del mercado a través de los siguientes cuatro grupos de trabajo técnico:

- User Working Group.

- Architecture y Infrastructure Design Working Group.

- Data Analysis Working Group.

- Advisory Committee.

\subsubsection{Hipotecas verdes en España}

Las hipotecas verdes en España fueron introducidas primeramente por Triodos Bank en el año 2013. Con anterioridad denominada Ecohipoteca, vinculaba el tipo de interés con la calificación energética de la vivienda. El banco de procedencia holandesa es la única entidad financiera que ofrece este tipo de hipoteca en el Estado Español. En la actualidad, renombrada Hipoteca Triodos, vincula el tipo de interés a la calificación energética de la vivienda (A-G), lo cual significa que cuanto más eficiente es la vivienda, a menor tipo de interés estará sujeta la hipoteca. Triodos Bank ofrece dos tipos de hipotecas, una mixta y una de interés variable.

\section{¿Cómo solicitar un préstamo hipotecario verde en España?}

En la Hipoteca Triodos Mixta, el interés está vinculado a la certificación energética. Con un interés fijo y conocido los primeros 10-15 años, y uno variable los siguientes (considerando un euríbor $+1.05 \%$ ). Después se aplicará un tipo de interés variable resultado de añadir al tipo de referencia (Euríbor diario a 12 meses) el diferencial que corresponda, de nuevo, en función de la calificación energética de la vivienda. En la Hipoteca Triodos Variable, los primeros 18 meses están sujetos a un TIN fijo de $2.25 \%$. Concluido ese período, se ha de revisar anualmente.

El tipo se vincula al Euríbor (Euríbor diario a 12 meses) más un diferencial asociado a la certificación energética de la vivienda. En el cálculo de las TAE Variables se incluye, además, la tasación del inmueble (400€ aprox.) y la verificación registral $(10 €)$. Cabe destacar que, en ambos casos, si a lo largo de la hipoteca se reforma la vivienda y mejora su calificación energética, se revisará a la baja el tipo de interés que se paga por ella.

Existen otras entidades bancarias que ofrecen productos similares a los de Triodos, cuyas tipologías se explican en la Figura 11. 


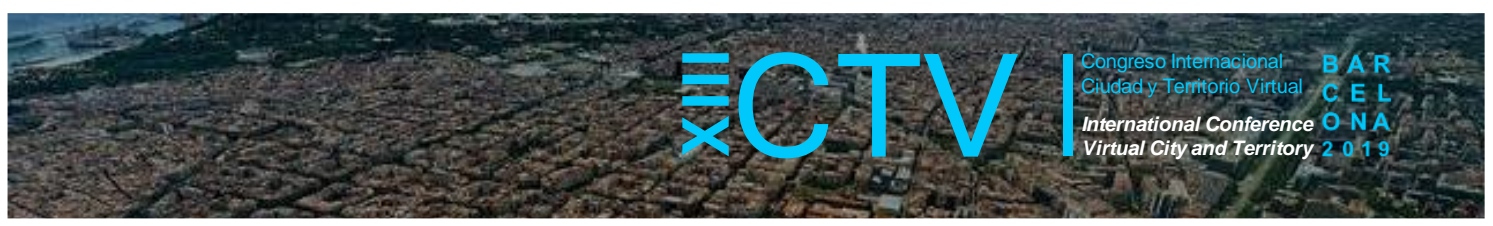

Figura 11. Selección de ecotecnologías

\begin{tabular}{|c|c|c|c|c|c|c|c|}
\hline BANCO & $\begin{array}{l}\text { TIPO DE } \\
\text { BANCO }\end{array}$ & $\begin{array}{l}\text { NOMBRE } \\
\text { DEL } \\
\text { PRODUCTO }\end{array}$ & BENEFICIARIO & TIPO DE OBRA & $\begin{array}{l}\text { TIPO DE } \\
\text { EDIFICACIÓN }\end{array}$ & $\begin{array}{l}\text { EE CON TIPO } \\
\text { DE INTERES }\end{array}$ & ENLACE \\
\hline $\begin{array}{l}\text { Triodos } \\
\text { Bank }\end{array}$ & Banco & $\begin{array}{l}\text { Hipoteca } \\
\text { Triodos }\end{array}$ & Particulares & $\begin{array}{l}\text { Obra nueva y } \\
\text { rehabilitación }\end{array}$ & Vivienda & $\mathrm{SI}$ & $\begin{array}{l}\text { https://www.triodos.es/e } \\
\text { s/hipotecas- } \\
\text { triodos/hipoteca-variable }\end{array}$ \\
\hline $\begin{array}{l}\text { Caixa } \\
\text { Ontinyent }\end{array}$ & Caja & $\begin{array}{l}\text { Préstecs per } \\
\text { a la millora } \\
\text { de l'eficiència } \\
\text { energètica }\end{array}$ & Particulares & Rehabilitación & $\begin{array}{l}\text { Vivienda, } \\
\text { Comercio, } \\
\text { Industrias. }\end{array}$ & SI & $\begin{array}{l}\text { https://www.caixaontiny } \\
\text { ent.es/va/pages/prestec- } \\
\text { eficiencia-energetica- } \\
\text { autonoms }\end{array}$ \\
\hline ABANCA & Banco & $\begin{array}{l}\text { Préstamos } \\
\text { Eficiencia } \\
\text { Energética }\end{array}$ & Empresas & Instalaciones & Negocio & NO & $\begin{array}{l}\text { https://www.caixaontiny } \\
\text { ent.es/va/pages/prestec- } \\
\text { eficiencia-energetica- } \\
\text { autonoms }\end{array}$ \\
\hline $\begin{array}{l}\text { Caja de } \\
\text { Ingenieros }\end{array}$ & Caja & $\begin{array}{l}\text { Préstamos } \\
\text { ECO }\end{array}$ & Particulares & Rehabilitación & Vivienda & NO & $\begin{array}{l}\text { https://cajaingenierossi } \\
\text { muladores.afi.es/cajaing } \\
\text { enieros/LoanReport.asp } \\
\text { x?lang=es-ES }\end{array}$ \\
\hline $\begin{array}{l}\text { Banco } \\
\text { Santander }\end{array}$ & Banco & $\begin{array}{l}\text { Prestamos } \\
\text { BEI } \\
\text { Eficiencia } \\
\text { Energética }\end{array}$ & Empresas & Instalaciones. & Negocio & NO & $\begin{array}{l}\text { https://www.bancosanta } \\
\text { nder.es/es/empresas/fin } \\
\text { anciacion/proyectos- } \\
\text { empresariales/prestamo } \\
\text {-bei-eficiencia- } \\
\text { energetica }\end{array}$ \\
\hline
\end{tabular}

Fuente: Elaborado por los autores.

\section{Eficiencia energética e impago de hipotecas. Enfoque de competitividad en el mercado convencional}

La literatura analizada ha permitido reconocer las diversas alternativas de financiamiento verde con las que cuenta el propietario o inquilino de un inmueble residencial en la actualidad. Este financiamiento en forma de préstamo, bono o subsidio sugiere un cambio en la matriz de consumo energético en la vivienda, un beneficio en su nivel de calidad de vida y, por tanto, una utilidad económica tangible una vez realizadas las renovaciones de eficiencia energética. No obstante, antes de poner en evidencia la relación entre la ventaja económica mensual del rendimiento energético y los riesgos de impago de hipotecas por efectos de la reforma, es imprescindible descomponer la problemática por los actores involucrados.

Desde la perspectiva de Sanderford, et al. (2015), el actor crítico de la estructura hipotecaria es el prestamista por encima de los desarrolladores inmobiliarios, constructores y compradores, debido al capital que pone en riesgo. Máxime en el mercado de las hipotecas verdes, ya que como bien señalan Aroul y Hansz (2011), el mercado de la vivienda ha comenzado a traducir la presencia de tecnologías de eficiencia energética y etiquetas ecológicas en precios más altos para los inmuebles. Sin embargo, Sanderford, et al. (2015) sostiene que en la actualidad la difusión de la eficiencia energética residencial se encuentra disminuida por razones como las fricciones del mercado y la desinformación de los prestamistas frente a las finanzas verdes, impidiendo las oportunidades de la ventaja competitiva privada y la transparencia del mercado. Como ejemplo, el mercado de la vivienda eficiente en Estados Unidos aún no ha sobrepasado el $16 \%$ del mercado, marcándose como una demanda inicial que compra la eficiencia como una novedad más que como una mejora concreta para su vivienda, evidenciando la incapacidad de diferenciar en el mercado inmobiliario las viviendas eficientes energéticamente de las convencionales. Asimismo, Koebel (2013) menciona que existe una concepción errónea del uso de hipotecas verdes en EE. UU, ya que es posible que el mercado de viviendas con eficiencia energética se esté materializando en familias de bajos ingresos que primen menores gastos mensuales en facturas de energía, aunque se vean obligadas a vivir en la periferia. De este modo, lo que estas familias hacen es una compensación entre la ineficiencia de la ubicación residencial respecto al centro urbano y el beneficio de un menor gasto energético. 


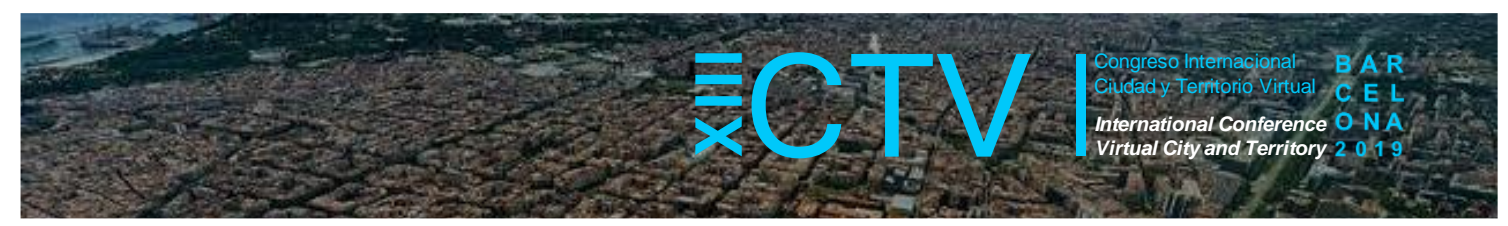

Además, desde el contexto financiero, Simons et al. (2009) corrobora que otra de las acciones que impiden la correcta adopción de las viviendas energéticamente eficientes en el mercado es la injusta competencia de las hipotecas verdes con créditos de consumo, subsidios estatales e incentivos fiscales, incitando a los compradores y prestamistas a volcarse casi totalmente a la oferta y demanda convencional. Por ende, queda expuesto que gran parte de la irregularidad de adopción de viviendas sostenibles se debe a la valoración fragmentada del mercado, resultando en un obstáculo para el prestamista hipotecario que no encuentra confiabilidad en el ámbito de la construcción ecológica y el ahorro energético. Ahora bien, profundizando en la relación de las hipotecas verdes y el riesgo de impago, Kaza (2013) analiza dos aspectos de riesgos hipotecarios (impago y pago anticipado). El autor ha estudiado la relación entre el índice HERS (Home Energy Rating System) de eficiencia energética de Energy Star y el impago de hipotecas. Este índice evalúa la eficiencia energética de los hogares en una escala del 0 en adelante, otorgando el nivel 0 a aquellos hogares de consumo nulo.

Utilizando un modelo de regresión como metodología, los resultados arrojan que, al controlar otros factores, una mayor eficiencia energética -medida por una disminución de un punto en la puntuación HERS- se asocia con una disminución en el riesgo de incumplimiento en un $4 \%$ y en la de riesgo de prepago en un $2 \%$. Los préstamos convencionales tienen mayores riesgos de impago y pago anticipado en comparación con los respaldados por el gobierno (incluidos Fannie Mae y Freddie Mac), probablemente porque estos préstamos tienden a tener términos y servicios más favorables. Las tasas de desempleo locales se asocian positivamente con los riesgos de incumplimiento en el modelo de regresión donde se analiza el índice HERS (ver Tabla \#7). Si bien los ingresos más bajos del vecindario aumentan las tasas de incumplimiento y pago anticipado, los efectos son sustancialmente pequeños, el autor también señala que las casas con valores más altos que la media del vecindario exhiben menos morosidad y mayor propensión al pago anticipado. En general, los resultados sugieren que la eficiencia energética sí importa, ya que, al reducir los gastos en la factura energética de los hogares, los modelos sugieren que los propietarios de hogares posiblemente continuarán cumpliendo sus obligaciones hipotecarias.

Figura 12. Modelo de regresión con índice HERS

\begin{tabular}{|c|c|c|c|c|c|c|c|c|}
\hline \multirow[b]{2}{*}{ Varible } & \multicolumn{4}{|c|}{ DEFAULT } & \multicolumn{4}{|c|}{ PREPAY } \\
\hline & Estimute & $\begin{array}{l}\text { Sed. } \\
\text { Err. }\end{array}$ & Sig & $\begin{array}{l}\text { Ouds } \\
\text { Ratio }\end{array}$ & Extimute & Sed. Err. & Sig & $\begin{array}{l}\text { Odds } \\
\text { Ratio }\end{array}$ \\
\hline Intercept & 10.25 & 1.19 & $\ldots$ & & -0.49 & 0.74 & & \\
\hline FicO Score & -0.02 & 0.00 & $\cdots$ & 0.98 & 0.00 & 0.00 & $\cdots$ & 1.00 \\
\hline $\begin{array}{l}\text { Loun Originution After } \\
2006\end{array}$ & -3.76 & 0.18 & $\cdots$ & 0.02 & -2.29 & 0,15 & $\cdots *$ & 0.10 \\
\hline $\begin{array}{l}\text { Original Loun-to-Value } \\
\text { Ratio }\end{array}$ & 0.30 & 0.44 & & 1.35 & -1.19 & 0.25 & $\cdots *$ & 0.30 \\
\hline Loun Type & 0.58 & 0.09 & $* *$ & 1.78 & 0.22 & 0.06 & $* *$ & 1.24 \\
\hline $\begin{array}{l}\text { Zip Code Average } \\
\text { Unemployment }\end{array}$ & 0.02 & 0.01 & & 1.02 & -0.05 & 0.01 & $\cdots *$ & 0.95 \\
\hline $\begin{array}{l}\text { Zip Code Average } \\
\text { Income }\end{array}$ & 0.00 & 0.00 & $* *$ & 1.00 & 0.00 & 0.00 & . & 1.00 \\
\hline $\begin{array}{l}\text { House Price Relative } \\
\text { to Zip Code Sule Price }\end{array}$ & -0.18 & 0.08 & * & 0.83 & 0.10 & 0.04 & * & 1.11 \\
\hline Cooling Degree Days & 0.00 & 0.02 & & 1.00 & -0.07 & 0.01 & $\cdots$ & 0.93 \\
\hline Heating Degree Days & -0.04 & 0.02 & * & 0.96 & 0.00 & 0.01 & & 1.00 \\
\hline Electricity Price & 0.01 & 0.01 & & 1.01 & -0.02 & 0.01 & $* *$ & 0.98 \\
\hline Area of the House & 0.01 & 0.00 & * & 1.01 & 0.02 & 0.00 & $\cdots$ & 1.02 \\
\hline Age of the House & -0.01 & 0.02 & & 0.99 & -0.07 & 0.01 & $* *$ & 0.94 \\
\hline HERS Score & 0.04 & 0.01 & $\cdots$ & 1.04 & 0.02 & 0.00 & $* *$ & 1.02 \\
\hline
\end{tabular}

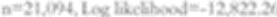

$\cdots *_{p}<00.001, * p<-0.01, * p<-0.05, p<=0$.

Fuente: Home Energy Efficiency and Mortgage Risks. Kaza (2013). 


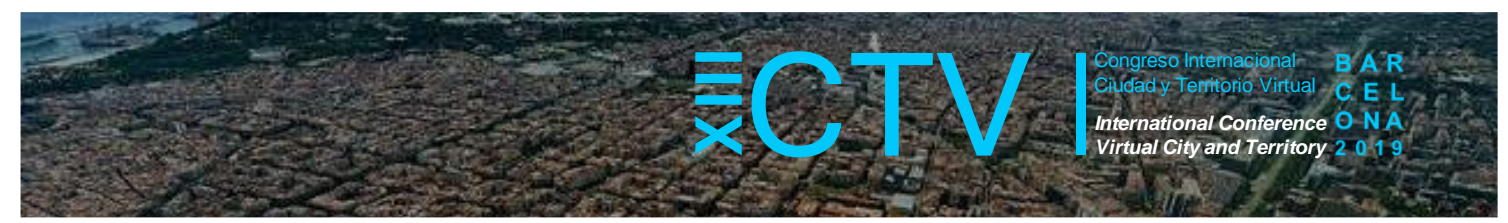

Desde otra perspectiva, Nevin (2010) propone en su estudio "Energy-efficient housing stimulus that pays for itself" una estrategia de ecoeficiencia para el programa Making Home Affordable. Dicho programa estadounidense tiene como objetivo eliminar los juicios hipotecarios mediante la incorporación de un sistema de mejoramiento energético con financiamiento de 75,000 millones de dólares, para que las viviendas que se encuentran en situación de litigio puedan pagar la deuda hipotecaria con el ahorro generado en la reducción de las facturas energéticas. El plan Making Home Affordable propone apoyar a los prestamistas con dinero para reducir el interés e impuesto hipotecario de los deudos y llegar a controlar la deuda mensual por debajo del $38 \%$ de sus ingresos. Además, plantea brindar a los acreedores 1,000 dólares anuales para la amortización de sus gastos hipotecarios, beneficiando a entre 3 y 4 millones de personas.

Las dos alternativas que propone el estudio son:

- Alternativa 1: Invertir 75,000 millones de dólares en la implementación de ventanas Energy Star en casas antiguas, lo que permitiría apoyar a 6.7 millones de personas. Esto beneficiaría también al mercado de la construcción en 61,000 millones de dólares y 2,000 millones en ahorro de energía. Esta estrategia se enfoca al bien inmueble y no en la deuda que pasa a ser del usuario, lo cual regula el mercado.

- Alternativa 2: Promover la idea de Samuelson (2009), quien manifiesta que "la mejor manera de prevenir los juicios hipotecarios es estimulando el mercado inmobiliario". La idea es implementar viviendas que se encuentran justamente en juicios hipotecarios con ventanas Energy Star y otros elementos de ahorro de energía para fomentar a los first buyers a comprar estas viviendas con intereses menores.

La literatura revisada evidencia que, si bien es lógico suponer que las posibilidades de impago hipotecario en viviendas con eficiencia energética son mínimas, por la situación de ventaja económica en relación al menor consumo energético, es el mismo esquema de sostenibilidad energética el que puede resolver problemas de impago de hipotecas convencionales, demostrando el potencial de mercado que tienen los programas de eficiencia energética si se adoptan correctamente.

\section{Otros instrumentos de política de financiamiento}

\subsection{Programa Green Deal}

El Green Deal era un programa de eficiencia energética de origen británico ligado a la Energy Company Obligation, que entró en vigor en enero de 2013 según la normativa Energy Act (2011) y el Plan Nacional de Mitigación de Emisiones (2011). Estaba dirigido a mejoras de aislamiento y rehabilitaciones parciales de 14 millones de viviendas para obtener edificaciones más eficientes en el ámbito energético, con el fin de promover la reducción de emisiones de carbono en el horizonte del año 2020. Aunque era una iniciativa alentadora para el ahorro energético residencial, el financiamiento público del Green Deal se canceló en julio de 2015 (Department for Energy and Climate Change, 2011).

\section{Regulación}

En sus inicios, el programa se planteaba con base en que las viviendas del Reino Unido, que llevan décadas construidas, eran mucho menos eficientes que sus homólogas europeas. En términos estadísticos, 10 millones (43\%) de los techos británicos carecían de revestimiento o fueron mal revestidos y 8 millones de viviendas tenían paredes que no habían sido aisladas (United Kingdom Government, 2011). 


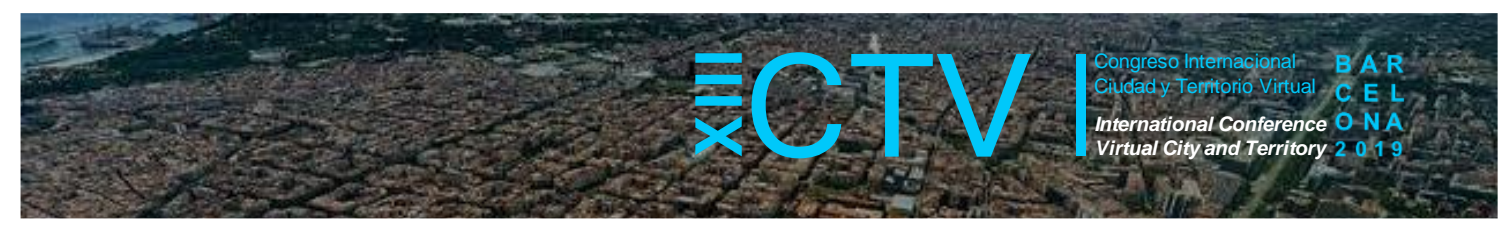

El esquema de comercialización del Green Deal tenía como fundamento la posibilidad de acceso a mejoras de eficiencia energética en viviendas, cuyos trabajos de rehabilitación serían pagados con los ahorros en la factura de electricidad, una vez que las cuentas de consumo de luz y gas comenzaran a bajar. La Regla de Oro inicial del programa involucraba que el pago total de la intervención no podía exceder el monto de la inversión inicial. El rango de la tasa de interés por las mejoras iba desde el $7.9 \%$ al $10 \%$, cuyo pago se podía prorratear a un período de $10-25$ años. En cuanto a la transferencia de responsabilidad, el préstamo se asignaba al usuario y, por tanto, en caso de venta/alquiler del inmueble, la responsabilidad se transfería al nuevo titular del inmueble. El Green Deal tenía un esquema con un componente privado fuertemente ligado a su estructura funcional, por lo que la administración solo se encargaba de autorizar y certificar a los agentes implicados. Así, todo el proceso de rehabilitación o aislamiento se producía directamente entre el usuario y las empresas asesoras/proveedoras (United Kingdom Government, 2018).

\section{Difusión}

La divulgación del programa Green Deal fue realizada en todo el territorio británico y tuvo como principales agentes de transmisión de información a los dirigentes barriales locales, puesto que cada zona habitada tenía diferentes capacidades para la adopción de tecnologías bajas en carbono. Aunque el alcance de la difusión de programa Green Deal se estima en todo el Reino Unido, la implementación de sus políticas no fue geográficamente uniforme debido a diversos factores socioculturales. En ese sentido, Morton et al. (2017), a través de un diagnóstico de la variación geográfica y temporal en las evaluaciones domésticas de eficiencia energética, identificó que los factores que sustentaron la difusión espacial del programa verde británico fueron principalmente: la presencia de familias jóvenes, residentes con educación universitaria, hogares separados y hogares grandes. Sin embargo, toda la tarea de difusión no implicaba que los usuarios accedieran al financiamiento de medidas energéticas mediante el Green Deal, con lo cual, la proporción de la difusión no era la misma que la de planes financiados (ver Figura 13).

Figura 13. Número de evaluaciones y planes financiados Green Deal

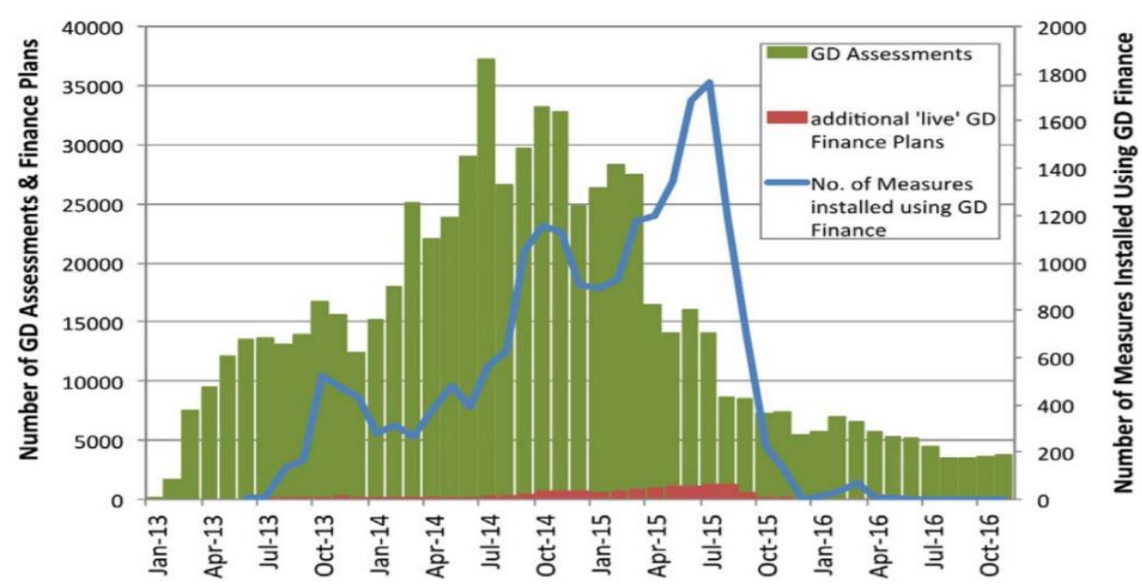

Fuente: Department for Business, Energy and Industrial Strategy (2017).

En cuanto a la difusión geográfica, en la Figura 14 se ilustra la dinámica espacial en la aceptación de evaluaciones Green Deal en los distritos electorales de Westminster Parliamentary Constituencies (WPC) entre septiembre de 2013 y junio de 2015. La variabilidad geográfica en la aceptación de evaluaciones verdes es claramente visible. Las ciudades de Londres y Westminster muestran los niveles más bajos de evaluación debido a que estas ciudades ya contaban con una industria residencial renovada y altos niveles de eficiencia energética. 


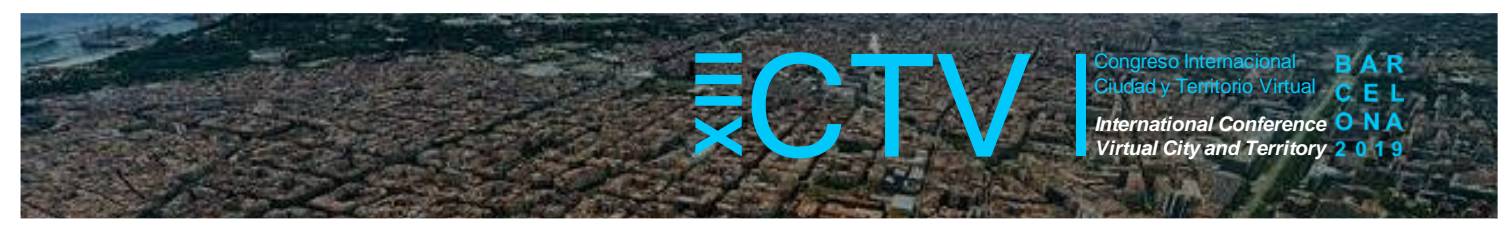

Figura 14. Difusión de evaluaciones Green Deal en los distritos electorales de WPC

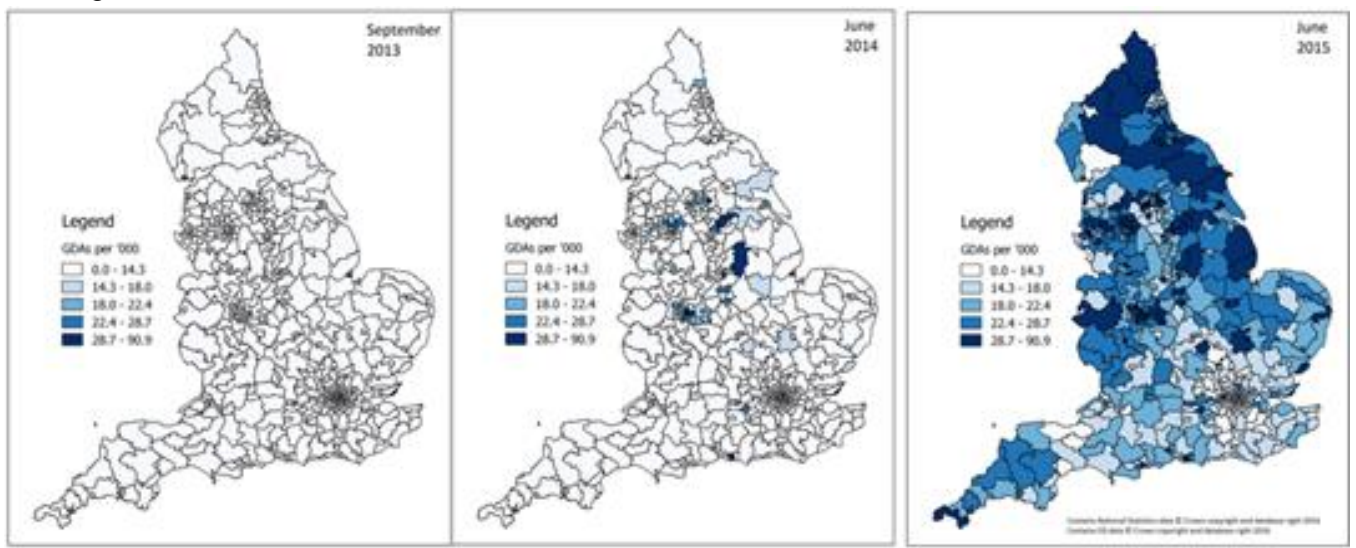

Fuente. The diffusion of domestic energy efficiency policies: A spatial perspective. Morton et al. (2018).

\section{Aplicación}

El proceso para acceder a los trabajos de rehabilitación iniciaba cuando el usuario acudía a un Proveedor Autorizado Green Deal como agente encargado de acompañar la asesoría, el contrato, la instalación y los informes de Calificación Energética. Este primer paso dependía íntegramente del usuario, ya que cada Proveedor Autorizado tenía diferentes tasas de interés según sus márgenes de beneficios.

Una vez contratado el Proveedor Autorizado, este se encargaba de contratar a un Asesor Certificado Green Deal, quien evaluaba la vivienda según los usos de energía y verificaba las propuestas de mejoras a realizarse. En este punto, el Asesor Certificado producía un informe de Acuerdo Ecológico que comparaba el consumo existente con el consumo programado una vez realizadas las mejoras. Para ello utilizaba un software aprobado por el programa Green Deal llamado RdSAP. En este punto del proceso, el usuario aún podía abstenerse de continuar la intervención si creía que la evaluación de su vivienda no le convenía financieramente, o proseguir con la elaboración del Green Deal Plan, que era un documento contractual que incluía los trabajos que se iban a realizar, el cálculo de rentabilidad económica y el interés fijo marcado por el Proveedor Autorizado. Firmado el contrato, el Proveedor Autorizado asignaba a un Instalador Certificado Green Deal para que iniciara los trabajos de instalación de mejoras de eficiencia energética en la vivienda. Después de haber finalizado la instalación, el Proveedor Autorizado proporcionaba un informe de Calificación Energética comparado con el informe de Acuerdo Ecológico realizado por el Asesor Certificado, para verificar que las propuestas de mejoras iniciales hubieran sido las mismas que el Instalador Certificado colocaba. Finalmente, si la comparación era positiva, el Proveedor Autorizado confería la Calificación Energética a la vivienda y realizaba la actualización del registro con cargo en la factura a la empresa proveedora de energía (ver Figura 15).

\section{Causas de cierre}

A pesar del intento del gobierno británico de lograr un programa público que apoyara la sostenibilidad y el cuidado del medio ambiente, el Green Deal tuvo muy poca aceptación por parte de la población llevándolo a su desaparición. El inicio fue prometedor puesto que se realizaron más de 300,000 asesorías energéticas, pero el problema apareció en el momento de la implementación de las propuestas de mejora energética en las viviendas. Menos del $2 \%$ de todas las asesorías que se realizaron fueron concretadas en proyectos de implementación de mejoras, produciendo un déficit de presupuesto público en el programa. 


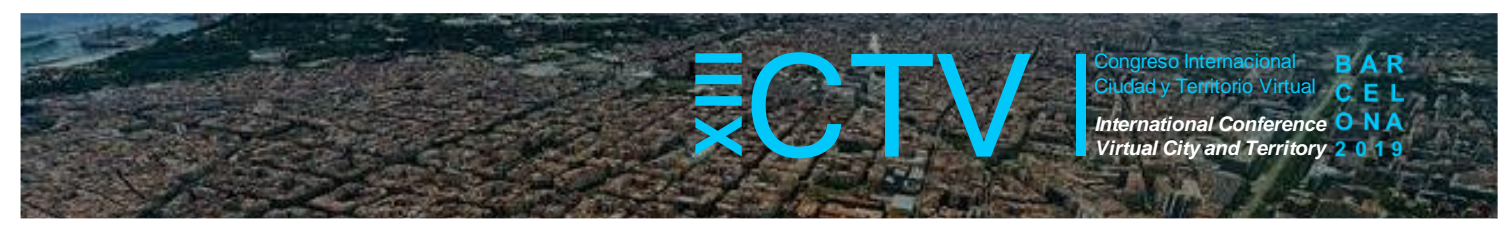

Entre las razones y fallos principales del cierre del esquema energético Green Deal en julio del 2015, Rosenow y Eyre (2016) encontraron: 1) la eliminación de la Regla de Oro desde el inicio de su aplicación, lo que originó confusiones y percepción de engaño en la población; 2) el sistema de categorización financiera impidió el acceso al programa a personas de bajos recursos que, por vivir en las peores condiciones de aislamiento térmico, quizás eran los más interesados; 3 ) las tasas de interés del Green Deal eran más altas que las del sistema financiero convencional; 4) la política no fue bien comunicada al público general; $y, 5$ ) fueron excluidos muchos inquilinos por la resistencia de los propietarios a participar de las medidas de mejora, particularmente en las viviendas menos eficientes energéticamente de los inquilinos más pobres.

\section{Figura 15. Proceso de funcionamiento del programa Green Deal}

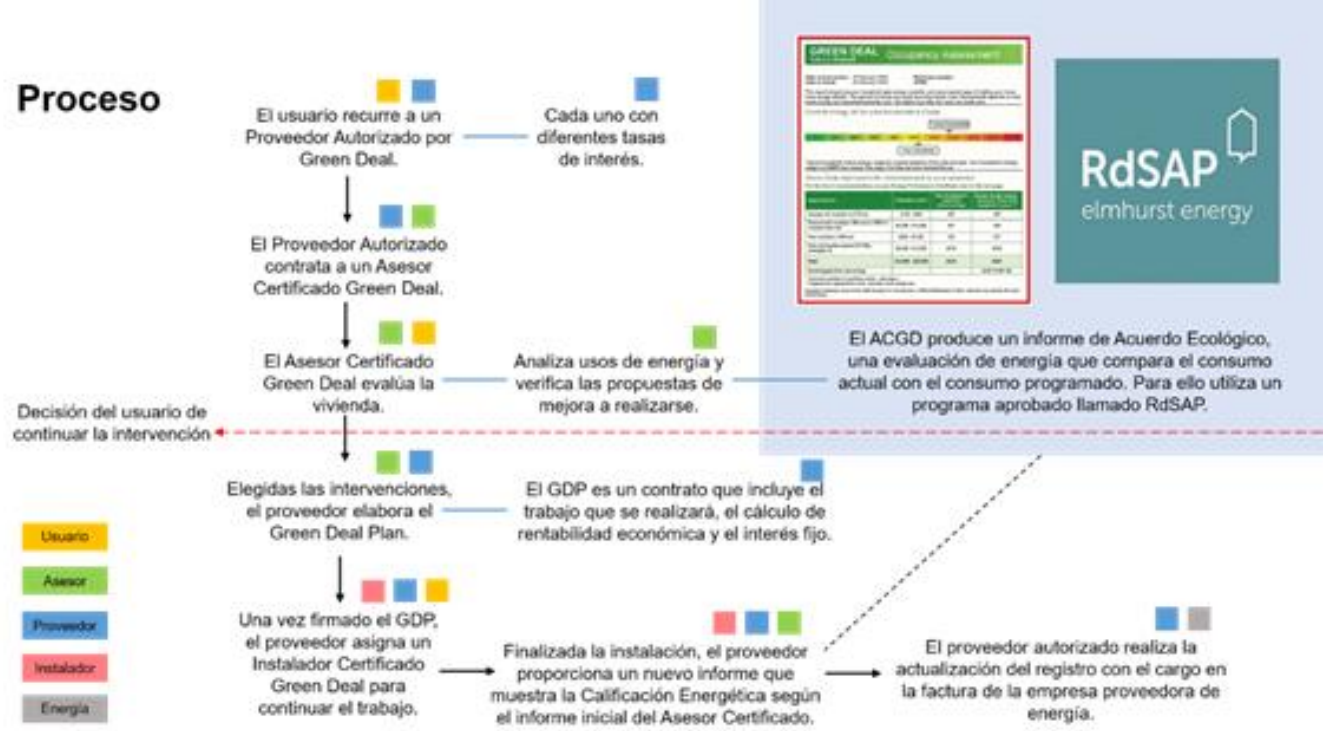

Fuente: Elaboración de los autores con datos del Green Deal.

\subsection{Proyecto EnEv}

Alemania por su parte, cuenta con el "Reglamento Alemán de Ahorro Energético" (EnEv). Según información de Weiss-Technik (2019), el EnEv es un programa que se enfoca en el ahorro energético de los edificios, más concretamente basado en los aspectos térmicos, asociados con el aire acondicionado, agua caliente, iluminación, diseño bioclimático y energías renovables. El programa evalúa el consumo energético y las emisiones en edificios residenciales y no residenciales y está a cargo del Ministerio Federal de Transporte, Edificación y Desarrollo Urbano, y del Ministerio de Economía y Tecnología. Aparece como reglamento oficial en 2002, pero sus orígenes se remontan al año 1995, experimentando distintas modificaciones en su estructura hasta llegar a constituirse como el programa actualmente conocido.

A partir del año 2002, los edificios residenciales existentes están regulados por los estándares energéticos establecidos en las directivas del EnEv y, por tanto, serán necesarios trabajos de renovación para elementos de aislamiento como paredes, techos, suelos, el mantenimiento de instalaciones de agua caliente y fría y el reemplazo obligatorio de calderas con más de 30 años de antigüedad. En caso de que el propietario no pueda pagar las reformas, el Estado puede financiar la renovación, con un préstamo del $4 \%$ de interés anual. 


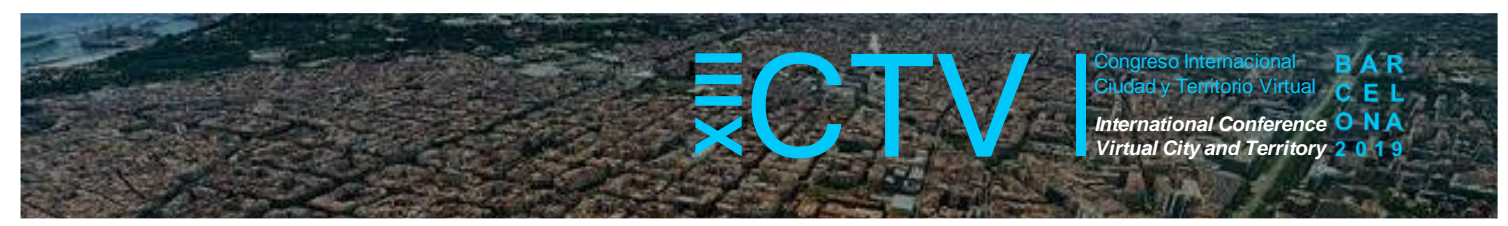

\section{Discusiones: regulación, difusión y aplicación}

\section{Regulación}

El financiamiento por bonos verdes no presenta una estandarización global, sin embargo, ha comenzado la búsqueda hacia la homogeneización de criterios por medio de la creación de iniciativas y organizaciones privadas que se encargan de generar manuales y certificaciones que promuevan la emisión de bonos, dado que la certificación es uno de los pilares para ganar la confianza de los inversores. En el caso de las hipotecas, la inexistencia de un sistema de certificación único internacional sobre la eficiencia energética dificulta la creación de una estructura de instrumentos de financiación verde consistente y sólida. La etiqueta común para toda la Unión Europea, también está lejos de ser una realidad, dado que demanda un mismo marco normativo de calificación, lo cual es una dificultad por las diferencias (sobre todo de índole geográfica) entre lo que es energéticamente eficiente o no en los diferentes países.

\section{Difusión}

Existe todavía una desinformación con respecto a este tipo de productos. Por ejemplo, el estudio de la historia de las hipotecas verdes en USA muestra lo engorroso del acceso a este tipo de producto, convirtiéndose así una iniciativa poco exitosa. A su vez, en Europa, la historia de las hipotecas verdes es relativamente reciente, por lo que no se está todavía en disposición de información que apoye su desarrollo. Entendemos que esta incertidumbre por parte de las entidades financieras incide en una baja oferta de productos, aún con la intención de los gobiernos en fomentar los productos de financiación verde. En España, después de todo el proceso EeMap que fue fruto del Acuerdo de París, sólo se ha conseguido que un banco (Triodos Bank) ofrezca una hipoteca que cumple con todos los requisitos para denominarse verde, según los parámetros de los programas antes citados.

Por el contrario, encontramos que la difusión del mercado de bonos verdes es más accesible. Existen plataformas que se encargan de hacer públicos informes sobre los bonos emitidos por países y las supranacionales, de igual manera exponen los últimos acuerdos, convenciones y asambleas realizadas en cuanto al cambio climático. El crecimiento del mercado de bonos verdes ha sido especialmente lento en América Latina. Las barreras evidenciadas en la literatura disponible son: altas tasas de inflación, poco desarrollo del mercado de capital, una legislación que no otorga garantías necesarias para la seguridad del inversionista, entre otras; todo aquello, en un contexto de inestabilidad política.

\section{Aplicación}

Lograr la armonización entre la rentabilidad y el desarrollo de actividades responsables, y que el primer factor no se convierta en un obstáculo para el desarrollo del segundo, es uno de los grandes problemas para la aplicación efectiva de instrumentos de financiación verde, que se mueven entre dos intereses a veces divergentes como son la rentabilidad y responsabilidad ambiental.

En USA, el mercado de la vivienda ha comenzado a traducir la presencia de tecnologías de eficiencia energética y etiquetas ecológicas en precios más altos para los inmuebles. Esto supondría que, al tener un valor mayor, estas viviendas y sus hipotecas han de resultar inaccesibles para los grupos poblacionales que más se beneficiarían de la reducción de las facturas de energía. Con respecto a la localización de las viviendas asociadas a hipotecas verdes, se observa una relación con la dispersión urbana. Por ejemplo, gran parte de las viviendas financiadas por la hipoteca verde mexicana se localizan en las periferias de las ciudades, con los consabidos problemas de movilidad e ineficiencia que hacen aumentar 


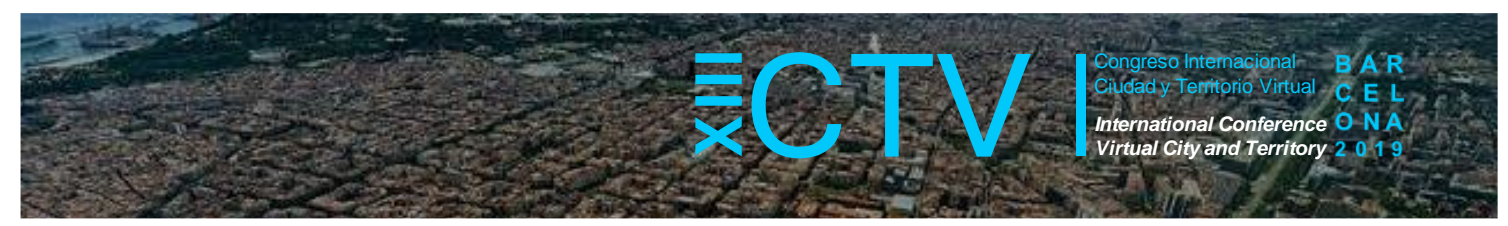

igualmente la huella de carbono y el consumo de energía. En USA ocurre lo mismo, observando dinámicas como la de la reducción del monto de la hipoteca por parte del usuario alejándose de los centros y asentándose en la periferia.

\section{Recomendaciones}

En los últimos años, la aparición de productos de financiación verde ha tenido relativo éxito; aun así, parte de la responsabilidad sobre la poca oferta de productos, es de la falta de información y estudios al respecto. Es importante generar nuevas líneas de investigación que aborden el ámbito del financiamiento verde en diversas vertientes, tales como la posibilidad de estandarización de productos o etiquetas, la difusión de información sobre los productos existentes, o la elaboración de estadísticas que permitan documentar el éxito o fracaso de dichos productos.

Agradecimientos: Los autores extienden su agradecimiento a los estudiantes de Economía Urbana del Máster en Gestión y Valoración Urbana (2018-2019) de la Universidad Politécnica de Catalunya por su colaboración en la recolección de información para este documento.

Contribuciones de los autores: Del primer al cuarto autor el trabajo de investigación se desarrolló en conjunto. El primer autor desarrolló la estructura de redacción y la elaboración de la discusión y recomendaciones; el quinto autor realizó la revisión del trabajo y observaciones puntuales sobre el hilo conductor del documento.

Conflicto de Intereses: Los autores declaran que no hay conflicto de intereses.

\section{Bibliografía}

Anderson, A., (2019). Ambiguity in securitization markets. Journal of Banking y Finance, 102, 231-255. https://doi.org/10.1016/.j.jbankfin.2019.03.015

Aroul, R., \& Hansz, J. (2011). The Role of Dual-pane Windows and Improvement Age in Explaining Residential Property Values. The Journal of Sustainable Real Estate, 3(1), 142-161. DOI: $\underline{10.2307 / 24860586}$

Banga, J., (2019). The green bond market: a potential source of climate finance for developing countries. Journal of Sustainable Finance and Investment, 9(1), 17-32. DOI: 10.1080/20430795.2018.1498617

BloombergNEF, (2018). La emisión de bonos verdes supera los $\$ 100$ mil millones para el tercer año. Recuperado de https://about.bnef.com/blog/green-bond-issuance-exceeds-100-billion-3rdyearl

Climate Bonds Initiative, (2018). Bonos y cambio Climático, Estado del Mercado 2018. Recuperado de https://www.climatebonds.net/files/files/CBI SotM 2018 Spanish.pdf

Comisión Europea, (2016). Finanzas Sostenibles. Recuperado de https://ec.europa.eu/info/business-economy-euro/banking-and-finance/sustainable-finance es

Department for Business, Energy and Industrial Strategy, (2017). Household Energy Efficiency National Statistics. Recuperado de https://www.gov.uk/government/collections/householdenergy-efficiency-national-statistics 


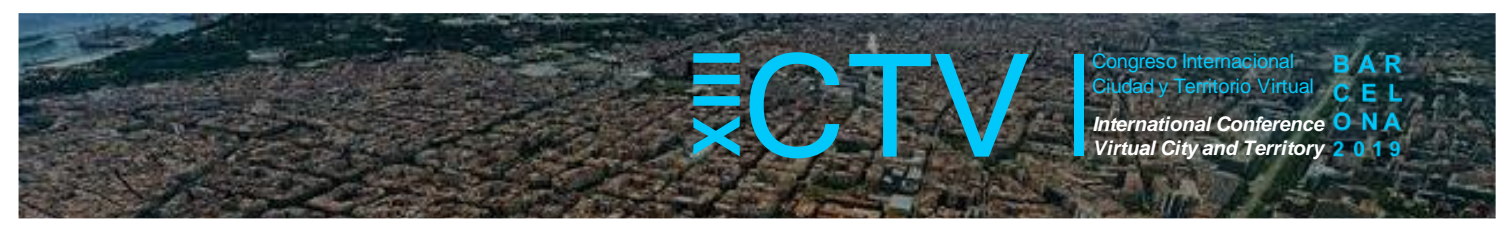

Department for Energy and Climate Change, (2011). Energy Act 2011 Part. 1 - Energy Efficiency. Chapter 1 - Green Deal. The Stationery Office Limited. London, United Kingdom.

EeMAP - Energy Efficient Mortgages Action Plan, (2018) The Initiative. Recuperado de https://eemap.energyefficientmortgages.eu/services/

Financial Stability, Financial Services and Capital Markets Union, (2018). Final report of the HighLevel Expert Group on Sustainable Finance. Recuperado de https://ec.europa.eu/info/publications/180131-sustainable-finance-report en

García E., (2019). Bonos Verdes, en crecimiento exponencial. Recuperado de http://www.finanzas.com/noticias/economia/20190507/bonos-verdes-crecimiento-exponencial$\underline{\text { 4018658.html }}$

Gianfrate, G., \& Peri, M. (2019). The green advantage: Exploring the convenience of issuing green bonds. Journal of Cleaner Production, 219, 127-135. https://doi.org/10.1016/j.jclepro.2019.02.022

Global Climate Action Summit, (2019). Resultados de la cumbre. Recuperado de https://www.un.org/en/climatechange/un-climate-summit-2019.shtml

Grupo Banco Mundial, (2015). ¿Qué son los bonos verdes? Disponible en: http://documentos.bancomundial.org/curated/es/165281468188373879/pdf/99662-

REPLACEMENT-FILE-Spanish-Green-Bonds-Box393223B-PUBLIC.pdf

Hernández, E., (2017). Préstamos verdes, una herramienta para financiar el desarrollo sostenible. Recuperado de https://www.bbva.com/es/que-son-prestamos-verdes-que-financian/

Hussain, T., (2018). Green Loan Principles to Guide Environmental and Sustainability Finance. Recuperado de https://www.whitecase.com/publications/alert/green-loan-principles-guideenvironmental-and-sustainability-finance

Iberdrola, (2019). ¿Qué son los bonos verdes y para qué se utilizan? Disponible en: https://www.iberdrola.com/sala-comunicacion/top-stories/inversiones-bonos-verdes

Infonavit, (2019). Hipoteca verde. Recuperado de https://portal.infonavit.org.mx/wps/wcm/connect/infonavit/trabajadores/cuido mi casa/hipoteca+ verde

Infonavit, (2019). Historia del Instituto. Recuperado de http://portal.infonavit.org.mx/wps/wcm/connect/infonavit/el+instituto/el infonavit/historia.

International Capital Market Association, (2017). The Green Bond Principles 2017. ICMA París Representative Office.

Kaza, N., (2013). Home Energy Efficiency and Mortgage Risks. Department of City and Regional Planning University of North Carolina at Chapel Hill.

Koebel, C. T., McCoy, A. P., Sanderford, A. R., Franck, C. T., \& Keefe, M. J. (2015). Diffusion of green building technologies in new housing construction. Energy and Buildings, 97, 175-185. https://doi.org/10.1016/J.ENBUILD.2015.03.037

Lam, P., \& Law, A., (2018). Financing for renewable energy projects: A decision guide by developmental stages with case studies. Renewable and Sustainable Energy Reviews, 90, 937944. DOI: $10.1016 /$ i.rser.2018.03.083

López Herrera, F., Ortiz, E., \& Cabello, A. (2009). Las interrelaciones de volatilidad y rendimientos entre los mercados de valores del TLCAN. Investigación Económica, 68(267), 83-114. DOI: $\underline{10.2307 / 42777643}$ 


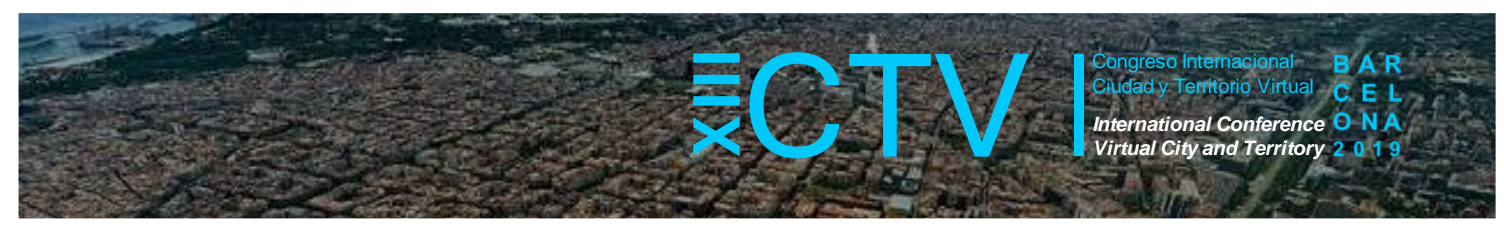

McInerney, C., \& Bunn, D., (2019). Expansion of the investor base for the energy transition. Energy Policy, 129, 1240-1244. DOI: 10.1016/i.enpol.2019.03.035

Morton,C., Wilson, C., \& Anable, J., (2017). The diffusion of domestic energy efficiency policies: A spatial perspective, Energy Policy 114 (2018) 77-88. DOI: 10.1016/i.enpol.2017.11.057

Nevin, R., (2010). Energy-efficient housing stimulus that pays for itself. Energy Policy, 38, 4-11. DOI: $10.1016 /$ j.enpol.2009.09.013

ONU, (2018). COP 24 ¿Qué está en juego en la cumbre del clima y qué debes hacer? Disponible en: https://news.un.org/es/story/2018/11/1446711

Programa de Estudios Económicos e Información, (2019). Mercado de bonos verdes ¿Quiénes son sus protagonistas?

Reboredo, J., (2018). Green bond and financial markets: Co-movement, diversification and price spillover effects. Energy Economics, 74, 38-50. https://doi.org/10.1016/..eneco.2018.05.030

Rosenow, J., Eyre, N., Sorrell, S., Guertler, P., (2017). Unlocking Britain's First Fuel: The Potential for Energy Savings in UK Housing. UK Energy Research Centre. Recuperado de http://www.cied.ac.uk/wordpress/wpcontent/uploads/2017/09/3900 UKERC CIED briefing fina l.pdf

Rosenow, J., y Eyre, N., (2016). A postmortem of the Green Deal: Austerity, energy efficiency, and failure in British energy policy. Energy Research \& Social Science, 21, 141-144. https://doi.org/10.1016/i.erss.2016.07.005

Samuelson, R., (2009). Wrong Turn on Housing. The Washington Post, p. A17.

Sanderford, A., Overstreet, G., Beling, P., \& Rajaratnam, K., (2015). Energy-efficient homes and mortgage risk: crossing the chasm at last? Environment Systems and Decisions, 35(1), 157-168. https://doi.org/10.1007/s10669-015-9535-8

Santander, (2018). ¿Sabes qué son las finanzas verdes? Disponible en: https://www.santanderpyme.com.mx/detalle-noticia/sabes-que-son-las-finanzas-verdes.html

Simons, R., Choi, E., y Simons, D., (2009). The Effect of State and City Green Policies on the Market Penetration of Green Commercial Buildings. The Journal of Sustainable Real Estate. American Real Estate Society. https://doi.org/10.2307/24860547

Unión Europea, (2019). Directiva 93/76/CEE del Consejo, de 13 de septiembre de 1993, relativa a la limitación de las emisiones de dióxido de carbono mediante la mejora de la eficacia energética (SAVE). Recuperado de https://eur-lex.europa.eu/legalcontent/ES/TXT/?uri=CELEX:31993L0076

Unión Europea, (2019). Plan de Acción: Financiar el Desarrollo Sostenible. Recuperado de https://eur-lex.europa.eu/legal-content/ES/ALL/?uri=CELEX\%3A52018DC0097

United Kingdom Government, (2011). London, United Kingdom: gov.uk. Carbon Plan. https://assets.publishing.service.gov.uk/government/uploads/system/uploads/attachment data/fi le/47621/1358-the-carbon-plan.pdf

United Kingdom Government, (2018). London, United Kingdom: gov.uk. Green Deal: energy saving for your home. Recuperado de https://www.gov.uk/green-deal-energy-saving-measures

Weiss-Technik a Schunk Company, (2019). Reglamento alemán de ahorro energético (ENEV).

World Bank, (2018). Green Bond Impact Report. Recuperado de http://pubdocs.worldbank.org/en/632251542641579226/report-impact-green-bond-2018.pdf 